\title{
The Common Sense Model of Illness Self-Regulation: A Conceptual Review and Proposed Extended Model
}

\author{
Martin S. Hagger ${ }^{1,2}$ and Sheina Orbell ${ }^{3}$ \\ ${ }^{1}$ Department of Psychological Sciences, University of California, Merced \\ ${ }^{2}$ Faculty of Sport and Health Sciences, University of Jyväskylä \\ ${ }^{3}$ Department of Psychology, University of Essex
}

\section{Full reference}

Hagger, M. S. \& Orbell, S. (2021). The common sense model of illness self-regulation: a conceptual review and proposed extended model. Health Psychology Review.

https://doi.org/10.1080/17437199.2021.1878050

\section{Disclosure statement}

No potential conflict of interest was reported by the authors.

\section{ORCID}

Martin S. Hagger http://orcid.org/0000-0002-2685-1546

Sheina Orbell http://orcid.org/0000-0002-8665-3541

\section{Funding}

Martin Hagger's contribution was supported by a Finland Distinguished Professor (FiDiPro) award (Dnro 1801/31/2105) from Business Finland.

\section{Correspondence}

Correspondence concerning this article should be addressed to Martin S. Hagger, SHARPP Lab, Psychological Sciences, University of California, Merced, 5200 N. Lake Road, Merced, CA 95343, email: mhagger@ucmerced.edu 


\begin{abstract}
The common sense model of illness self-regulation outlines the dynamic processes by which individuals perceive, interpret, and respond to health threats and illness-related information. An extended version of the model is proposed, which specifies additional constructs and processes to explain how lay perceptions of health threats impact coping responses and health-related outcomes. The extended model provides detail on: (a) the mediating process by which individuals' illness representations relate to illness outcomes through adoption of coping procedures; (b) how illness representations are activated by presentation of healththreatening stimuli; (c) behavioral and treatment beliefs as determinants of coping procedures and illness outcomes alongside illness representations; and (d) effects of moderators of relations between cognitive representations, coping procedures, and illness outcomes. The extended model sets an agenda for future research that addresses knowledge gaps regarding how individuals represent and cope with health threats, and may inform effective illnessmanagement interventions. We identify the kinds of research required to provide robust evidence for the extended model propositions. We call for research that employs incipient illness samples, utilizes designs that capture dynamic processes in the model such as crosslagged panel and intervention designs, and adopts illness-specific measures of coping procedures rather than relying on generic instruments.

Keywords: Self-regulation theory; Parallel-processing model; Social cognition; Illness perceptions; Illness cognition; Coping procedures
\end{abstract}




\section{The Common Sense Model of Illness Self-Regulation: A Conceptual Review and}

\section{Proposed Extended Model}

Detecting, processing, and responding to information signaling a potential threat to health are fundamental processes that are not only necessary for maintenance of everyday functioning, but for survival. Understanding these processes is a priority concern for healthcare organizations interested in developing models of care aimed at promoting health, and preventing and managing illness (Hagger, Moyers, et al., 2020; Johnson \& Acabchuk, 2018; Leventhal et al., 2008). As illness management moves away from inpatient care to selfmanagement, patients bear an increasing burden of the responsibility for their own treatment. Successful treatment for illnesses and health conditions is, therefore, increasingly dependent on patients' capacity to regulate their own treatment regimens (Horne \& Weinman, 1998; Leventhal et al., 2016). In addition, understanding how individuals monitor and respond to information and stimuli regarding health threats may inform early detection of acute illness (e.g., stroke, sepsis, meningitis), avoid delay in responding to illness symptoms (e.g., sexually-transmitted infections, cancers) or symptoms signaling exacerbation of existing conditions (e.g., swollen legs in congestive heart failure), and to address non-completion of treatment or non-attendance at medical appointments in prevention of chronic illnesses. For example, maximizing attendance to cancer screening programs and associated treatment is reliant on at-risk individuals' capacity to respond to illness threat information (Anagnostopoulos et al., 2012; Orbell et al., 2004; Orbell et al., 2006; Orbell et al., 2008). Gaining insight into individuals' lay beliefs or representations of health threats and illnesses is paramount to this understanding. Beliefs play a central role in motivating individuals' decisions to seek treatment or engage in actions directly aimed at addressing the threat (Carver et al., 1989; Leventhal et al., 1980). Conversely, beliefs may also be implicated in threat responses that may lead to failure to engage in treatment-seeking behavior, actions 
that are erroneous or ineffective in addressing the threat, or denial or minimization of the threat, which may have serious implications for prevention and prognosis of serious illness (Hagger, Koch, et al., 2017; Leventhal et al., 1998). Facilitating understanding of patients' beliefs and how they impact treatment decisions is, therefore, fundamental to informing the development of interventions that may be effective in promoting adaptive, treatment-seeking behavior (Cameron et al., 2020; Horne et al., 2013; Leventhal et al., 1992). Patients are also often faced with complex or ongoing treatment related decisions, and understanding beliefs that guide these decisions is important for care management.

The common sense model of illness self-regulation is a prominent social cognition approach to describing the processes by which patients' form lay beliefs about health threats, how the beliefs impact coping procedures, and how subsequent appraisals of these procedures, iteratively and dynamically, update beliefs and assist in managing the perceived threat (Clatworthy et al., 2007; Leventhal et al., 1980; Leventhal et al., 2016). Two types of beliefs, cognitive and emotional, are identified in the model and are proposed to operate in parallel, and interactively, in determining coping procedures. The model takes an individual perspective, recognizing that illness management is highly, sometimes exclusively, dependent on individuals' motivation to respond to manage threat. Importantly, the lay beliefs and associated coping responses make sense to the individual, even though they may be inconsistent with an 'expert' illness model and, therefore, erroneous or ineffective as a response to a health threat. The model has been extremely influential in advancing knowledge on how patients self-regulate health threats, and has been applied extensively to management of acute and chronic illness (Dempster et al., 2015; Hagger, Koch, et al., 2017; Hagger \& Orbell, 2003; Mc Sharry et al., 2011). Although the original purpose of the model was to describe how people make sense of health threats and illnesses, and their coping responses, it has also been used to describe how illness beliefs relate to illness outcomes (e.g., illness 
progression, perceived health, functioning, psychological well-being) through the selection of coping procedures, which may, ultimately, determine the course of the illness and prognosis.

The model is also evolving, encompassing additional constructs and processes that more effectively and comprehensively explain the processes by which patients' make sense of health threats and regulate their responses (e.g., Benyamini \& Karademas, 2019; Cameron et al., 2005; Durazo \& Cameron, 2019; Hagger, Koch, et al., 2017; Karademas et al., 2011; Leventhal et al., 2016; Moss-Morris, 2013; Orbell et al., 2006; Orbell et al., 2015; Orbell \& Phillips, 2019; Phillips et al., 2013). Many of these additions represent formal specification of Leventhal et al.'s (1980) original proposals, while others seek to extend the model to increase its scope and predictive validity. In the present article, we provide a critical review of the common sense model and the extant research testing its hypotheses, and propose an extended version of the model that clarifies and broadens its predictions. First, we elucidate and formally operationalize some key processes identified in, or inferred by, the original model. Second, we identify some key moderating factors that influence model processes contextual and dispositional factors. Third, we outline how explicitly differentiating between sets of beliefs in the model, such as beliefs regarding performing coping behaviors and treatment beliefs, may facilitate understanding of the determinants of coping behaviors and the processes involved. We expect our extended model to set an agenda for future research applying the model to explain how individuals respond to, and cope with, health threats.

\section{The Common Sense Model}

\section{Development of the Model and Basic Processes}

The common sense model arose from Leventhal et al.’s (1980) proposals to understand how individuals' responses to health threats relate to actions taken to deal with them. According to the model, individuals' coping responses to stimuli signaling threat are guided by cognitive representations of the illness formed by information stored in memory 
relating to illnesses, and individuals' cognitive processing of threat-related information. These representations of illness are proposed to be schematic and acquired through experience (e.g., bodily sensations, past illness history, interactions with others). Sources of information on health threats can be endogenous, such as experienced symptoms and somatic responses, or come from external sources, such as messages presented in pamphlets or television advertisements. Information can also be derived from other expert and lay sources, such as a doctor informing a patient of a diagnosis, reading about an illness in a newspaper, or having a conversation with a colleague about a friend's illness. Symptoms or somatic responses, indicating sharp deviation from normal functioning, are considered most likely to catalyze a response. Threatening information may activate associated illness-related information stored in memory and, if the information is perceived as posing a significant threat to health, may motivate individuals to form an appropriate coping response. The basic processes of the common sense model are depicted in Figure 1.

A distinction is made between the abstracted information relating to illnesses stored in long-term memory and the specific mental representations of illness activated by the illnessrelated stimuli (Henderson et al., 2007; Henderson et al., 2009; Leventhal et al., 1980; Leventhal et al., 2016). Information regarding illnesses is stored schematically in memory as illness prototypes, constructed over time from personal and vicarious experience, and social and cultural knowledge of the illness. Representations are a temporarily available mental model of the illness informed by currently available illness-related information and the stored prototype. Experience of a stimulus indicating a potential health threat, such as a headache or tightness in the chest, activates aspects of illness prototypes with similar symptoms such as those for the common cold or influenza. This 'matching' process likely results in the activation of representations or schema for illness with reasonable fit with the stimuli. Stored knowledge on procedures to cope with the illness, and associated action plans to enact them, 
may also be activated, leading to fast and efficient initiation of a coping response such as taking analgesic medication or to lie down in a dark room. Ambiguous information may lead to the activation of multiple representations, which may result in the individual evaluating the merits of the available coping responses and selecting the one with the best fit, or holding off on taking definitive coping procedures until more information comes to light. These processes are dynamic and iterative, with appraisals of coping effectiveness providing salient information to guide coping efforts and illness representations.

\section{Representations, Coping, Appraisals, and Outcomes}

Given that illness representations reflect individuals' lay or 'common sense' models of an illness (c.f., Hampson et al., 1995; Hampson et al., 1990), the selection of coping procedures ${ }^{1}$ in response to the representation will also make 'common sense' to the individual, even if the response is contraindicated from the perspective of an 'expert' illness model. Individuals monitor effects of the selected coping response for changes relating to illness progression, such as changes in symptoms or somatic information ("Has my illness or condition got better?"), or changes communicated by health professionals or medical diagnoses ("What do the test results show?"). If little or no change is detected in the symptoms or other potentially threatening illness-related indicators, or, worse, the symptoms or indicators signal further progression, the individual may opt to adapt or modify the coping procedure. For example, the individual may opt to prolong the selected coping procedure based on their appraisals (e.g., "I didn't perform it [the treatment] long enough and need to be

\footnotetext{
${ }^{1}$ Coping in the context of the common sense model refers to specific coping procedures, usually particular behaviors such as taking medication or engaging in treatment, and the action plans needed for individuals to enact them. However, it should be noted that research applying the model has tended to adopt definitions of coping from the broader coping literature, which includes specific behaviors, but also other more generalized and non-specific strategies (see Carver et al., 1989; Folkman \& Lazarus, 1988). Researchers have often classified these into active or problem-focused coping and passive or emotion-focused coping categories (see Hagger, Koch, et al., 2017; Hagger \& Orbell, 2003). However, such a distinction is not explicitly made in the common sense model, and we focus on coping procedures as any means adopted by individuals to manage or deal with a health threat. These procedures may involve specific behaviors aimed at managing the health threat, or procedures aimed at managing or avoiding the emotional response to the health threat.
} 
patient"), adjust the intensity (e.g., "the dose of [the treatment] was not optimal, so I will increase it"), or modify it (e.g., "I did not do [the treatment] correctly, I will do it a different way"). These alterations will also be constrained by the individual's beliefs about the ease, accessibility, and costs of the coping procedure. If appraisals of the effectiveness of the selected coping procedure against symptomatic and other illness-related information indicate little change, or even a worsening of the condition after several iterations of adjustment, then the individual may update their representation, consistent with model predictions (Clatworthy et al., 2007; Leventhal et al., 1980). This updating may alter the course of the coping response, or terminate it altogether. The iterative appraisal process, therefore, provides an ongoing means to guide individuals' coping response to mitigate health threats and restore health.

As an example of these processes, consider an individual with a headache. In the absence of other symptoms, he or she will likely match the representation to a 'headache' prototype, and not represent it as highly threatening. They may choose to either wait and see if the headache recedes, or take a mild painkilling medication. If the symptoms dissipate, the 'wait and see' or mild medication coping procedure would be appraised as effective, leading the individual to confirm their original representation as a minor headache and to acquire illness coherence. The experience will further reinforce the individual's headache schema, and the associated successful coping routine, stored in associative memory. If the headache symptoms persist, the individual will likely make alterations to their selected coping response, to perhaps see whether it can be carried out more effectively or more intensely. For example, the individual may rationalize that they did not give the medication enough time to work, did not wait long enough for it to work, or may identify mitigating factors that may still be causing the headache to persist (e.g., dehydration, stress), and may seek other concurrent actions to mitigate their influence (e.g., drink water, use relaxation techniques). If after 
several iterations in which the coping procedure is applied but is not appraised as effective in reducing headache symptoms, the individual may conclude that their representation was not correct in the first place, and subsequently seek to update it by searching for other illness prototypes that match the representation. This may, in turn, lead them to seek an alternative coping procedure for dealing with the health threat whose cause is uncertain, such as seeking medical attention. Appraisals, therefore, act as a dynamic feedback mechanism that permit ongoing updating of representations and coping responses according to changes in outcomerelated stimulus information (Leventhal et al., 1980; Martin et al., 2003). H. Leventhal (personal communication, January 18, 2018) has suggested that the ongoing appraisal of the effectiveness of the selected coping procedure and updating of threat representations is akin to a Bayesian process. Illness representations and prototypes represent 'priors' in the model while appraisals of success of coping procedures are used as posteriori information to adjust and update the representation and subsequent coping. The process is, therefore, a dynamic, iterative one with the purpose of arriving at the coping procedure that has the greatest likelihood of success in managing the health threat.

\section{Dimensions of Illness Representation}

Research on the common sense model has explored the content of cognitive illness representations. Multidimensional scaling studies (e.g., Bishop \& Converse, 1986; Linz et al., 1982) and open-ended interviews (e.g., Baumann et al., 1989; Croyle \& Jemmott, 1991; Lau \& Hartman, 1983; Meyer et al., 1985) have identified five distinct cognitive representation dimensions: cause, consequences, identity, personal control, and timeline. The cause dimension reflects beliefs about the causes of the illness such as genetics, infection, diet, environmental pollution, or risky behaviors; the consequences dimension reflects beliefs regarding the impact of the illness on everyday life such as physical and role functioning, work capacity, and personal relationships; the identity dimension reflects the symptoms and 
label given to the illness or condition; the timeline dimension describes the expected duration and time course of the illness or symptoms; and the personal control dimension reflects beliefs about whether the illness can be effectively cured or controlled by personal actions such as seeking help or taking medication. While each dimension is considered a separable aspect of the cognitive representation, they are also expected to be interrelated.

The representation dimensions have typically been measured using psychometric inventories such as the illness perception questionnaire (IPQ; Weinman et al., 2018; Weinman et al., 1996) and the personal models of illness interview (Hampson et al., 1990). Measures of the identity and causal attribution dimensions comprise lists of symptoms and potential causes, respectively. For the identity scale, individuals note on binary scales (yes vs. no) whether or not each symptom on the list has been experienced and can be attributed to the illness. The lists of symptoms are typically tailored to the illness or condition of interest, and also include items that are not medically related to the illness or condition of interest, which individuals may, nevertheless, attribute to the illness or condition (e.g., "pain", "sore throat", "nausea", "breathlessness" etc.). For the cause scale, individuals provide responses on standard psychometric scales to each listed cause, irrespective of whether the item is a verified cause of the illness or condition (e.g., "A germ or virus caused my illness"; "Pollution of the environment caused my illness"; "Stress was a major factor in causing my illness"). By contrast, measures of the consequences (e.g., "My illness has major consequence on my life"), control ("There is a lot I can do to control my symptoms"), and timeline (e.g., "My illness will last for a long time") dimensions use multi-item scales adjusted to make reference to the illness or condition of interest.

The inventories have been further adapted to include additional dimensions consistent with concepts in the common sense model. For example, important additional dimensions included in the revised illness perception questionnaire (IPQ-R; Moss-Morris et al., 2002) are 
treatment control and illness coherence. Treatment control reflects individuals' beliefs that treatment regimens (e.g., medicine, rehabilitation, health behaviors) will be effective in treating or managing the illness or condition. This dimension aims to capture control-related perceptions that focus on typical treatments, and isolate them from other control-related perceptions. This is derived from prior research that focused on specific forms of treatment control, such as beliefs about medication for illnesses and conditions for which medication adherence is a key treatment (e.g., Horne et al., 1999). Illness coherence taps patients' perceived clarity in understanding their illness (whether the illness 'makes sense'). As a meta-cognitive belief, the coherence dimension is set apart from other cognitive representation dimensions in that the extent of an individual's understanding of their illness or condition will likely have pervasive effects on their entire approach to coping. A further important development of the IPQ-R inventory is the introduction of a measure of emotional representations, which captures individuals' beliefs that thinking about the illness is associated with negative emotions such as anger, anxiety, depression, and worry ${ }^{2}$.

Taken together, the revised questionnaire provides a sample of generically-worded items that might be employed to assess relevant illness representation dimensions, and researchers are encouraged to modify the items so that they refer to the specific illness or condition of interest based on pilot work, extant literature, and medical knowledge (French \& Weinman, 2008; Moss-Morris et al., 2002; Weinman et al., 2018).

\section{Evidence for the Common Sense Model}

\section{Summarizing the Current Evidence}

\footnotetext{
${ }^{2}$ It is important to note that measures of the emotional representation dimension of the IPQ-R prompt respondents to reflect on their emotional responses to their illness (e.g., "the symptoms of my illness are distressing to me") as opposed to reporting their actual emotional responses (e.g., "I feel distressed"). The emotional representation dimension, therefore, taps individuals' reflections on their emotional responses to illness. To date, relatively little research has explored effects of actual emotional responses to illness, and the appraisals that give rise to these responses such as those identified in cognitive-motivational-relational theory of emotion (Lazarus, 1991), in the context of the common sense model.
} 
There has been a proliferation of research examining the tenets of the common sense model using illness representation measures alongside measures of coping responses and illness outcomes (for reviews see Hagger, Koch, et al., 2017; Hagger \& Orbell, 2003; Leventhal et al., 2011; Leventhal et al., 2016). Research has typically demonstrated positive correlations between measures of the illness representation dimensions that tend to signal a health threat (consequences, timeline, cause, identity, emotional representations) and maladaptive illness-related outcomes (e.g., anxiety, poor quality of life, low positive affect, illness progression), while representations reflecting less threat and beliefs in controllability (e.g., personal control, treatment control, coherence) are negatively related to these outcomes. Research has also shown that dimensions reflecting threat perceptions tend to be positively related to coping procedures that are not likely to lead to adaptive outcomes (e.g., avoidance, denial, emotion venting, seeking social support) and, surprisingly, negatively related to coping behaviors (e.g., visiting health professionals) or other coping procedures that might facilitate adaptive outcomes (e.g., cognitive reappraisal). Research on the causal attributions of illness has indicated similar patterns. For example, cardiac patients attributing their illness to stress-related causes (e.g., stress responses) are more likely to exhibit maladaptive outcomes (e.g., greater risk of heart attack, morbidity) (e.g., Affleck et al., 1987). However, cardiac patients who attributed their condition to behavior-related causes (e.g., poor health habits) were more likely to subsequently adopt adaptive coping behaviors (e.g., uptake of dietary and exercise) (e.g., Weinman et al., 2000). The personal control and coherence dimensions, on the other hand, have been found to be positively related to coping procedures likely to lead to adaptive outcomes, and negatively related to avoidant-oriented coping procedures.

These findings have been confirmed in meta-analytic research examining these sets of relations across multiple illnesses and populations (e.g., Dempster et al., 2015; Hagger, Koch, 
et al., 2017; Hagger \& Orbell, 2003), and in specific illnesses (e.g., Hudson et al., 2014; Mc Sharry et al., 2011). Together these studies seem to indicate that threat perceptions and emotional representations tend to be positively related to avoidant coping procedures, negatively related to coping procedures likely to lead to adaptive outcomes, and linked to maladaptive outcomes such as higher negative emotional responses, lower quality of life, and poorer functioning, reduced likelihood of treatment-seeking behavior, and increased illness progression. In contrast, control-related perceptions and more coherent beliefs regarding the illness are linked to greater use of coping behaviors and approach coping procedures, as well as better functioning, increased treatment seeking, reduced distress, and lower illness progression.

\section{Limitations and Boundaries of Current Evidence}

As these findings illustrate, the general trend within research applying the common sense model has been to focus on correlations between illness representation dimensions and coping responses and illness outcomes (e.g., Heijmans, 1999; Scharloo et al., 1998), or, in cases where multivariate analytic techniques were adopted (e.g., multiple regression, structural equation modeling), the unique effects of the dimensions on outcomes while accounting for the effects of the others (e.g., Hagger et al., 2005; Horne \& Weinman, 2002; Rutter \& Rutter, 2002). However, research examining how characteristic patterns of interrelations among the dimensions may determine coping procedure selection or outcome appraisals is limited by comparison. Such an approach may be more consistent with the original model in that representation dimensions are expected to be related in meaningful ways for each individual, reflecting their personal 'model' or 'theory' of their illness (Clatworthy et al., 2007; Leventhal et al., 1980). One alternative approach has been to examine whether distinct 'profiles' of illness representations exist, and whether these profiles are linked to the adoption of particular coping procedures. Research applying cluster analytic 
methods (see Clatworthy et al., 2007) has demonstrated how characteristic clusters of representation dimensions exist. For example, Hobro et al. (2004) identified an 'adaptor' illness representation cluster in chronic pain patients, defined by lower scores on timeline and emotional distress, and higher scores on personal and treatment control, and coherence, relative to a 'non-adaptor' cluster. Similar 'positive' and 'negative' cluster profiles have been identified in other studies (Crawshaw et al., 2015; Norton et al., 2014). 'Adaptor' and 'positive' illness perception profiles have been shown to be associated with better prognosis, recovery, and functioning as well as adoption of adaptive coping procedures (Crawshaw et al., 2015; Hobro et al., 2004; Norton et al., 2014). However, the clusters in these analyses were generated at the sample level, so do not capture individualized illness representation profiles as suggested by the model. The adoption of research methods that focus on singlecases such as N-of-1 designs (e.g., McDonald et al., 2017), which enable exploration of effects of individual profiles of beliefs on coping and outcome appraisals over time, might offer an alternative approach and may be a viable option for future research.

The extant research testing common sense model hypotheses has also been criticized by the preponderance of largely static correlational designs which do not account for change in representations, coping, and illness outcomes over time (DeLongis \& Morstead, 2019; Hagger, Koch, et al., 2017; Leventhal et al., 2016). Such research may not provide sufficient tests of model processes, particularly the mechanisms underpinning the role of coping as a mediator between representation and outcome, and the dynamic nature of the model including coping appraisals, as a mechanism for updating and modifying representations and ongoing coping procedure selection. Furthermore, research to date has not extensively tested potential interaction effects within the model, such as the moderating effects of emotional and cognitive representation dimensions (Leventhal et al., 2001), or extraneous variables such as individual differences and personality traits (e.g., Cameron et al., 1998; Karademas et al., 
2011; Moss-Morris et al., 2011), on the pattern of effects in the model. In the following sections, we propose revisions to how the common sense model is tested and outline some extensions to the model, based on recent theory and evidence, that may serve to provide tests that capture these key processes, often neglected in research applying the model, and also broaden its capability to explain the processes by which representations relate to coping responses and illness-related outcomes.

\section{Extending the Model}

\section{Overview of the Extended Model}

Our proposed extended model is presented in a generalized form in Figure 2. A prominent extension is the hypothesized mediation of the effect of representation dimensions, particularly the role of threat perceptions (e.g., consequences, identity, timeline), on illness outcomes by coping procedures. Although the mediation prediction was not a hypothesis made explicit in the original model, it was implied and provides a logical extension to model so that it captures the process by which illness representations guide coping and impact outcomes. We also extend the model by specifying interactive effects among emotional and cognitive representation dimensions. A further extension is formalization of the schematic structure of illness representations, and the process by which illness stimuli activate appropriate representation dimensions and concomitant coping procedures. These aspects of our extended model seek to provide a more comprehensive, formal description of existing model tenets, which can form a template for subsequent research testing these processes.

Consistent with recent approaches to theory integration (e.g., Ajzen \& Kruglanski, 2019; Hagger, 2009; Hagger \& Hamilton, 2020a; Hofmann \& Kotabe, 2012), we also introduce additional constructs and associated processes in the model to extend its predictive validity, particularly the conditions that determine selection of coping behaviors and approach-oriented responses resulting from representations of health threats. Specifically, we 
propose inclusion of beliefs with respect to specific coping behaviors as predictors of coping alongside illness representations. We also propose the inclusion of beliefs about treatment, such as beliefs in effectiveness, concerns, side effects, and overuse, and their impact on coping and outcomes independent of illness representations. Finally, we also explore the potential impact of socio-structural constructs (e.g., socio-economic status, ethnicity) in the model, and propose that such variables should be included as integral to model processes rather than as mere control variables.

\section{Coping as a Mediator}

\section{Theory and Evidence for Mediation}

As implied in the original common sense model, coping responses have been proposed to mediate relations between representations of health threats and illness outcomes (Hagger, Koch, et al., 2017; Hagger \& Orbell, 2003; Leventhal et al., 1980; Leventhal et al., 2016). The mediation effect is based on the premise that effects of illness representations on outcomes are due to the coping procedures individuals adopt to manage their illness.

Conceptually, individuals' representations of health threats motivate selection of common sense coping procedures to manage the threat and restore emotional equilibrium and maintain health. The coping procedures will be expected to affect a change in the course of indicators of the deviation from functioning. For example, a coping behavior such as taking medication or attending a clinic is likely to lead to a reduction in perceived illness progression or felt symptoms. A coping procedure such as distraction or seeking social support may lead to a reduction in distress and worry. The mediation process is illustrated in Figure 2 as the effects of cognitive representations, threat and control and coherence, and emotional representations on coping procedures, and the effects of the coping procedures on illness and affective outcomes. The mediation processes are also precursor to the re-appraisal process in which changes in outcomes and perceived effectiveness of the coping procedures serve as sources of 
information that stimulate updating of representations. For example, an individual who copes with asthma by regularly using prophylactic medication should experience a reduction in symptoms that will, in turn, lead her or him to update, or reappraise, their condition as more controllable and less threatening. The same process will follow in all subsequent coping attempts and appraisals of subsequent outcomes. The highly routinized association between the representation and coping procedure will likely manifest in the development of close associations between the illness representation and the coping procedure in memory and habitual use of the medication (Henderson et al., 2009; Orbell \& Phillips, 2019). Over time, the illness will be perceived to be highly controllable with low perceived consequences.

There is a relative dearth of formal tests of the mediation process. Tests have indicated that effects of representations indicating elevated threat (e.g., perceived consequences, identity, cause, timeline) on maladaptive outcomes is mediated by emotionfocused coping procedures (Benyamini et al., 2004; Evans \& Norman, 2009; Rutter \& Rutter, 2002), while effects of representations of personal and treatment control on adaptive outcomes tend to be mediated by problem focused-coping procedures (Rutter \& Rutter, 2002). However, few studies have demonstrated effects of threat perceptions on adaptive outcomes mediated by coping behaviors and approach-oriented coping procedures. This is noteworthy given that a fundamental prediction of the model is that threat perceptions should motivate individuals to take action to manage the threat. Studies reporting this pattern of effects are relatively scarce. As an example, Brewer et al. (2002) demonstrated that effects of the consequences representation dimension on hypercholesterolemic patients' cholesterol levels were mediated by their medication adherence. Similarly, research on causal attributions has demonstrated that internal, unstable, and controllable attributions were indirectly associated with positive psychological adjustment through the use of approach and emotion-focused coping procedures (Roesch \& Weiner, 2001). These findings 
notwithstanding, the majority of mediation tests indicate that coping behaviors and approachoriented coping procedures tend not to mediate relations between threat perceptions and outcomes. Furthermore, given the multidimensionality of illness representations, and the myriad of available coping responses, confining analyses to individual representation dimensions, coping procedures, and outcomes likely oversimplifies the process. Such analyses do not test the unique effects of the representation dimensions on outcomes, and do not enable tests of multiple coping procedures as mediators. Studies that are selective in the representation dimensions and coping procedures may result in inaccurate reflections of the true effects of representation dimensions on outcomes and the mediated effects through coping procedures.

\section{Updated Evidence for Mediation and a Meta-Analysis}

The relative dearth of tests of the mediation hypothesis in the common sense model, and even fewer testing multiple mediator models, indicated a need for research testing how multiple coping procedures serve to explain effects of illness representation dimensions on illness outcomes. Hagger, Koch, Chatzisarantis, and Orbell (2017) conducted a meta-analysis of 254 studies reporting effect sizes among illness representation dimensions (consequences, emotional representations, identity, illness coherence, personal control, timeline) $)^{3}$, coping responses (avoidance, cognitive reappraisal, emotion venting, problem-focused coping procedures, seeking social support), and illness-outcomes (disease state, distress, physical, role, and social functioning, well-being) in chronic illness. The matrix of meta-analytically synthesized correlations were subjected to a path analysis testing the multiple mediator model.

\footnotetext{
${ }^{3}$ The cause dimension was omitted from the analysis given the considerable heterogeneity in the items and scales used to measure this dimension.
} 
The analysis identified several important patterns of findings consistent with the common sense model. First, coping procedures were identified as mediators of effects of representation dimensions on illness outcomes, but direct effects of representations on outcomes remained, suggesting that coping procedures only partially accounted for representation-outcome relations. A possible explanation for these direct effects is the potential of other unmeasured coping or mediating variables that accounted for the residual effects of representations on illness outcomes. For example, it may reflect implicit beliefs that directly impact outcomes (e.g., individuals who believe that their illness is more serious may function less well). Alternatively, direct effects may also be indicative of measurement overlap with the representation dimensions and the measured outcomes, which is likely to be exacerbated in studies that measure these variables concurrently. Second, the analysis yielded some theoretically consistent patterns of effects, which were also in keeping with previous mediation analyses (e.g., Benyamini et al., 2004; Brewer et al., 2002; Evans \& Norman, 2009; Rutter \& Rutter, 2002), and patterns of correlations among model constructs from previous research (Dempster et al., 2015; Hagger \& Orbell, 2003; Mc Sharry et al., 2011). For example, positive effects of emotional representations on distress and negative effects on well-being were mediated by avoidance and emotion venting coping procedures. Positive effects of perceived control on adaptive outcomes, such as well-being, and physical and role functioning, were mediated by generic and illness-specific forms of coping procedure. These findings support the general conclusions of previous studies that threat-related perceptions relate to maladaptive outcomes mediated by coping procedures that focus on emotion control.

Interestingly, the overall effect of threat perceptions on illness outcomes such as distress, disease state, well-being, and functioning tended to be very small or zero. This seemed to imply that threat perceptions were not effective in motivating individuals to engage in approach-oriented coping procedures that will impact their illness. However, the 
multiple mediator analysis enabled estimation of specific indirect effects, which permitted isolation of mediated effects of each representation dimension on each illness outcome through each coping procedure dimension. The specific indirect effects revealed positive indirect effects of consequences, a threat representation, on functioning and well-being through approach-oriented coping procedures, and a negative indirect effect through avoidance. As a practical illustration, consider an osteoarthritic patient experiencing knee pain. The patient is likely to view the pain as indicative of potentially serious consequences for future mobility, but such pain may be a signal to engage in rehabilitation exercises prescribed by their physiotherapist, a coping behavior likely to lead to adaptive outcomes. This coping response is likely to be effective in improving future functioning and perceived well-being. However, adoption of an avoidance-oriented coping procedure in response to knee pain, may result in reduced functioning and undermine well-being.

A similar pattern of specific indirect effects, although with opposite signs, was found for consequences on disease state, a measure of illness progression, and distress through approach-oriented coping procedures and avoidance. For example, a patient with type II diabetes perceiving their condition as having a serious impact on future functioning, may adopt a coping behavior, such as moderating their dietary sugar intake or taking medication to manage glucose levels, which may reduce illness progression (e.g., lowered HbA1c measures) and moderate felt distress. Alternatively, although coping with the perceived serious consequences of diabetes through avoidance may moderate felt negative affect in the short term, such a response is likely to lead to increased illness progression, and ultimately to increased distress in the long term. Taken together these indirect effects suggested that the zero total effect of consequences on these outcomes observed in the overall indirect effects masked the true pattern of effects, and examination of the specific indirect effects enabled detection of these specific pathways. 
The analysis, therefore, indicated that representations of threat motivated individuals to adopt approach-oriented coping procedures, which were related to adaptive outcomes (c.f., Brewer et al., 2002). It also revealed that threat perceptions predicted coping procedures likely to lead to maladaptive outcomes such as avoidance, which were related to maladaptive outcomes. As the analysis was conducted across multiple illnesses and populations, the most probable interpretation is that the two pathways reach sufficient strength in different population groups or illness contexts for them to both emerge as significant in the aggregate analysis. So rather than the unlikely scenario in which both pathways occur simultaneously, a more likely explanation is that contextual and population-level factors determine whether individuals adopt an approach or avoidant coping response in relation to a threatening representation. A key avenue for future research arising from these findings, therefore, would be to identify the specific conditions that moderate the indirect effects of threat perceptions on illness outcomes through coping procedures; a moderated mediation effect (Hayes, 2018). For example, which factors determine whether arthritis or diabetic patients adopt approach or avoidant coping procedures in response to their perceptions of serious consequences, and have a bearing on adaptive or maladaptive outcomes? In summary, Hagger et al.'s (2017) mediation analyses serve to broaden the understanding of patterns of effects in the common sense model, and indicate that overreliance on bivariate relations or simple mediation models does not capture the complexity of effects in the model.

\section{Methodological Limitations and Recommendations for Future Mediation Tests}

The conclusion from Hagger et al.'s meta-analysis points to a general limitation of the research testing common sense model effects: a preponderance of correlational studies, which do not provide clear illustration of the order of mediated effects and preclude inference of causality (Hagger, Koch, et al., 2017). Causal effects in these studies are inferred from theory alone rather than the data itself. A number of authors have made similar observations (Hagger 
\& Orbell, 2003; Hoving et al., 2010; Leventhal et al., 2016). Researchers are, therefore, encouraged to adopt research designs that more appropriately capture effects as specified in the model. One possible approach would be to adopt a panel design enabling tests of reciprocal effects and staggered mediation effects. An example of a panel design to test some key hypotheses of the revised common sense model is illustrated in Figure 3. Specifically, the design allows the modeling of (a) the effects of the representation, coping, and outcome measures on themselves over time, known as 'autoregressive' effects, which provide information on the stability of the constructs; (b) reciprocal effects among model constructs through the cross-lagged effects, which provide information on how constructs in the system account for variance in others and vice-versa; and (c) prediction of outcomes over time, which tests hypothesized directional relations based on model predictions (Selig \& Little, 2012). Other than modeling temporal change in the variables, testing cross-lagged effects may provide insight into the dynamic nature of the appraisal process and capture how appraisal of changes in outcomes may inform updating of representations and coping responses. A panel design may also be useful to examine how relations among representations, coping, and outcomes change over an extended period of time. For example, measuring these constructs at three or more points in time may permit sequential mediation analysis, such that representation coping outcome relations, and reciprocal effects, links are assessed across time points (Preacher et al., 2006).

Although panel designs allow for the modeling of these effects across a number of discrete time points, it does not account for relatively rapid fluctuations and modifications in illness perceptions, coping, and outcomes over time. Alternative innovative approaches may be to adopt more frequent sampling of the constructs and a time phased analysis, using, for example ecological momentary assessment (Burke et al., 2017) or latent growth curve 
analysis to model effects of representation dimensions on outcomes over an extended period of time (Chilcot et al., 2020; Preacher et al., 2006).

In a similar vein, although there have been studies that have adopted experimental designs to test model predictions (e.g., Evans \& Norman, 2009; Heerema-Poelman et al., 2011; Karademas, 2012; Petrie et al., 2002), these studies also number relatively few. Manipulation of illness representation dimensions and examining effects on coping procedures will demonstrate how change in these constructs affects selection of coping procedures, outcomes, and subsequent beliefs about the illness. Changing illness representations may be difficult for patients with chronic illness and considerable experience with a particular illness, and it is also challenging for researchers to gain access to individuals at the exact point of onset of symptoms or provision of information regarding an illness. One possible research strategy would be to examine changes in illness representations during recovery or rehabilitation from acute illness and their relationship to outcomes such as return to work and normal functioning (e.g., Petrie et al., 2002). Another strategy might be to use hypothetical scenarios or priming to change or activate threat representations and examine effects on coping procedures and related outcomes (e.g., Henderson et al., 2007; Henderson et al., 2009; Orbell et al., 2015). Overall, adoption of innovative longitudinal and experimental designs would be an important step toward providing stronger evidence for the pattern of effects in the model, particularly testing for change in model constructs that may capture the dynamic nature of the model.

A further limitation of research testing mediation effects in the common sense model is an observed overreliance on generic coping measures. The original conceptualization of the common sense model had a clear focus on specific behaviors that patients need to adopt to manage health threats, and the action plans required to enact them. However, meta-analyses of research applying the model revealed that those that operationalized specific coping 
behaviors numbered relatively few (Hagger, Koch, et al., 2017; Hagger \& Orbell, 2003). Instead, researchers have tended to rely on standardized coping instruments (e.g., the COPE, Ways of Coping Checklist) that exhibit good psychometric properties, but only capture broad, generalized cognitive and emotional coping styles or tendencies (e.g., "I tried to do something about the problem" or "I made a plan and followed it"). Such instruments do not precisely capture the specific behaviors likely to bring about change in the course of the health threat. Furthermore, reliance on such measures likely introduces error in tests of model predictions and may lead to inaccurate conclusions. Together these limitations pose a significant barrier to progress in testing mediation and the development of effective interventions based on the model (Cameron et al., 2020). Consequently, we call for greater use of coping measures that are concordant with the specific coping behaviors advocated in the original model and correspond more closely with the illness under investigation and measures of illness representations.

\section{Links between Stimuli and Representations}

\section{Illness 'Schema' and Illness Stimuli}

According to the original conceptualization of the common sense model, information on health threats and illnesses originate from many sources (Baumann et al., 1989; Leventhal et al., 2005). The information may be somatic information signaling deviation from normal functioning that could be attributed to a health threat. Alternatively, the information may arise from external sources processed by the individual such as reading a pamphlet, seeing a television advertisement, or receiving information when in conversation. The information may be derived from experience of the illness vicariously through friends, family, or acquaintances. According to the common sense model, sources contribute to the development of a representation of illness that is stored schematically in memory, and represents generalized abstracted and stable information about the illness. Experimental evidence 
supports the proposition that illness information is schematically organized (Henderson et al., 2007).

For example, Henderson et al. employed a narrative priming method to 'activate' either common cold schema or cardiovascular disease schema in two experiments involving healthy participants. Compared to a control group that received a neutral non-illness prime, participants demonstrated attentional bias to concepts associated with the primed illness, but not to concepts related to the non-primed illness. Findings are consistent with the idea that an environmental prime or symptom might activate a particular illness prototype. The extent of attentional bias represented by interference of word meaning in color naming illness concepts, was positively associated with explicit threat representations of illness, suggesting that the extent to which an illness is represented as threatening governs attention to illnessspecific information. Contextual factors such as seasonality of illness, or public health campaigns, might also render particular illness schema more accessible and guide interpretation and response to symptoms (Orbell et al., 2015). These findings suggest that people do possess illness prototypes for well-known illnesses (correct or otherwise) but do not imply that these are not updated or unresponsive to new information in a flexible manner that involves interactions between consciously experienced and non-conscious processes.

\section{Illness Schema and Coping Procedures}

An active illness representation is a crucial precursor to taking action to regulate illness threat. For example, Leventhal, Leventhal, and Contrada (1998) suggested: "The representation of an illness can affect behaviour only when it is activated, though activation does not imply that the representation will be fully conscious" (p. 8). People are prompted to visit their local pharmacy or grocery store to buy throat lozenges or pain killers after they realize they are ill. The common sense model does not explicitly suggest that coping responses might be encoded in memory, but there is evidence that they may be capable of 
automatic activation along with an illness schema. When an illness schema is activated resulting in the individual suddenly realising that he or she is ill, it is likely that well learned coping responses previously used for the particular illness and appraised as effective will also be brought to mind. Consistent with this idea, Henderson, Orbell, and Hagger (2009) demonstrated that activation of a cold or 'flu' schema using subliminal priming resulted in heightened attention to the words 'lozenge' and 'Lemsip ${ }^{\mathrm{TM}}$, , representing typical strategies used to cope with a cold or 'flu, in a subsequent grammatical decision task amongst frequent users. Similarly, Ahluwalia, Hughes, McCracken, and Chilcot (2017) showed that a 'headache' prime influenced responses to the word 'paracetamol' in participants who had previously declared positive beliefs about the efficacy of paracetamol in the treatment of headache. An important observation in both studies is that attention to coping responses amongst participants with past use of Lemsip ${ }^{\mathrm{TM}}$ or paracetamol occurred only when the illness schema was also made accessible by priming. For commonly experienced symptoms, evidence suggests that coping procedures associated with illness experiences in the past are encoded as part of the illness schema and are activated when that illness schema is subsequently activated.

Laboratory studies have been effective in illustrating the schematic nature of illness representations, how illness-related information may activate the representations, and how information relating to coping may be stored concurrent with the representations and may be activated along with the representation (Henderson et al., 2009; Orbell et al., 2015; Orbell \& Phillips, 2019). However, to date there have been relatively few studies that have been effective in exploring these processes in field studies on patients. Capturing the processes by which illness-related information results in the activation of illness representations and concomitant selection of coping procedures presents considerable challenges to researchers given the difficulty of recruiting participants at the precise time they receive information 
relating to an illness or health threat. One strategy would be to develop a quasi-experimental design for conditions that are diagnosed through blood or genetic tests such as familial hypercholesterolemia or sexually transmitted infections like chlamydia. The fact that these conditions are typically asymptomatic in early stages controls for potential confounding effects of pre-diagnosis symptomatic information. Measures of illness representations would be taken prior to diagnosis, after, and at follow up some time later, with measures of coping procedures and illness outcomes administered post-diagnosis and at follow up. Individuals receiving a positive diagnosis would form the 'experimental' group, and those receiving negative results would serve as the 'control' or comparison group. Such designs would require considerable coordination with medical professionals, but could be achieved in conjunction with existing networks such as routine screening programs.

An example of this approach is provided in Orbell et al.'s (2008) study examining differences in illness representations in people receiving diagnostic information from health professionals after colonoscopy. Distinctive patterns of illness representation were observed in groups diagnosed with no neoplasia (absence of illness), adenoma (a benign tumor), or cancer. Representations in turn were associated with use of escape or avoidance, reappraisal, and change in coping behaviors. These types of study permit testing effects of diagnosis on activation of representation, selection of coping procedures, and, ultimately, adherence to treatment, and illness outcomes. Such studies extend laboratory-based research on the processes by which threatening information about a condition leads to the development or activation of representation dimensions and concomitant coping procedures selection in 'real world' settings.

\section{Behavioral and Treatment Beliefs}

Introducing Additional Beliefs in the Model 
Our extended model includes social cognition beliefs concerning future performance of specific coping behaviors, and beliefs about treatment, alongside beliefs about illnesses captured by the illness representation dimensions from the common sense model. Inclusion of these beliefs are consistent with the original conceptualization of the theory, but provide formal descriptions of predictions arising from the model or represent theory-consistent extensions. For example, inclusion of additional social cognition beliefs is consistent with research that has utilized constructs from other theories with those of the common sense model to provide testable predictions or links between representations, coping behaviors, and outcomes based on the original model or in keeping with its predictions (Hagger et al., 2016; Orbell et al., 2006; Sniehotta et al., 2010).

Similarly, precedence for the inclusion of treatment beliefs in the model can be found in the research literature on medication beliefs. Medication adherence has been studied as a specific coping behavior, and researchers have incorporated beliefs about medication as determinants of medication adherence as a specific coping behavior, particularly looking at beliefs about necessity and concerns (e.g., Horne et al., 1999). Our extended model includes treatment beliefs as a separate construct, to formally define hypotheses relating to treatment beliefs, but it is consistent with the original predictions of the model. It is also important to recognize that our focus in the extended model is on specific behaviors aimed at coping with the health threat, consistent with the original model. Behaviors include seeking advice from a health professional, screening attendance, taking medication, and participating in rehabilitation exercises.

\section{Beliefs About Behaviors}

According to the common sense model, individuals form illness representations that reflect the extent to which the illness or condition represents a threat, which may provide impetus to identify a behavioral coping response (Leventhal et al., 2016). If the individual's 
representation of their illness is sufficiently threatening and signals the need to take action, they will also form, or activate (see Henderson et al., 2009; Orbell et al., 2015; Orbell \& Phillips, 2019), representations of coping behaviors (Orbell et al., 2006). Researchers have proposed that such representations should encompass beliefs about the subsequent initiation and performance of specific coping behavior itself. These beliefs likely encompass the individual's evaluations of the utility and expected outcomes (for example; amelioration of symptoms, minimization of consequences) including affective dimensions of the behavior, personal capacity to engage in it, and the presence or absence of extraneous factors or social supports that may facilitate or inhibit participation. The considerations will correspond specifically to the behavior, and will be highly pertinent to its enactment relative to illness beliefs which signal a need to act rather than determining specific intentions to act.

The focus on beliefs about specific behaviors is consistent with the key tenet of the model that individuals' develop representations of potential coping responses. Leventhal et al. (2016) stated that "the same five sets of variables define treatment representations, both self-selected and medically prescribed" (p. 937). After recognizing a health threat, the individual may form or 'activate' a representation of a coping behavior, which comprises similar dimensions as the representation of the threat itself. For example, the individual may form representations of the label and experience with the coping action (identity), its potential effects on symptoms or unwanted side-effects (consequences), how long it will take to be take effect (timeline), and the extent to which it can be accessed and managed (control). However, measures of illness representations have tended not to encompass beliefs about coping behaviors. Some of the IPQ-R dimensions make some generalized reference to beliefs about coping actions. For example, the personal control and treatment control dimensions in the IPQ-R make reference to personal efficacy (e.g. "there are things I can do to control my illness") and treatability (e.g. "treatment can control my illness") with respect to coping with 
the illness, but do not reference specific behaviors or strategies. Furthermore, the measures do not consider other sets of beliefs that might govern the adoption of a coping response, such as its ease of performance or the extent to which it is socially supported.

We propose, therefore, that tests of the model explicitly incorporate beliefs about performance of specific coping behaviors. There has been a trend toward inclusion of measures of constructs that reflect beliefs about future performance of coping behaviors alongside representations of illness. Research integrating constructs from social cognition theories of intentional behavior, such as the theory of planned behavior (Ajzen, 1985), has been at the forefront of this trend (e.g., French et al., 2013; Hagger et al., 2019; Hagger et al., 2016; Hagger, Hardcastle, et al., 2018; Orbell et al., 2006). The inclusion of such constructs have the goal of incorporating the motivational processes that determine future participation in specific coping behaviors not encompassed by illness representations. Consideration of sets of beliefs relating to coping behaviors will provide important information on how patients evaluate available treatment options and facilitate better understanding of their choices. In the next section we outline the rationale for incorporating additional beliefs, and related mechanisms, into the revised common sense model and outline how such integration may advance understanding of illness coping.

Rationale for Including Beliefs about Behaviors. The potential role of beliefs in the selection of behavioral coping response was proposed by Leventhal et al. (1980) in the original conceptualization of the common sense model. For example, self-efficacy, an individual's belief in their capacity to act to attain a given outcome derived from Bandura's (1986) social cognitive theory, was proposed as a necessary determinant of a behavioral response to a health threat along with the representation of the threat. Incorporating such beliefs is important to understand the coping process that has seldom been accounted for in tests of the common sense model. Social cognition theories, which identify the antecedent 
factors that determine future participation in the behavior, offer fully-developed means to identify the specific sets of beliefs that determine coping behaviors, and chart the processes involved. We represent these original predictions of the common sense model in our extended version by integrating beliefs from a prototypical form of these theories, the theory of planned behavior (Ajzen, 1985), alongside representation dimensions with the goal of providing a more comprehensive account of the coping process.

The theory of planned behavior (Ajzen, 1985) identifies the belief-based antecedents of social behavior, and the processes by which the beliefs relate to behavior. Consistent with a social cognition approach in which behavior is assumed to be a function of prospective evaluations of future action (Seligman et al., 2013), the theory predicts that behavioral engagement is controlled by a reasoned process, represented by individuals' beliefs and intentions with respect to performing the behavior in the future. The key tenet of the theory is that behavior is a function of individuals' beliefs that engaging in a given behavior within a specific timeframe will result in desired or undesired outcomes, or attitudes ${ }^{4}$, beliefs regarding the social influence on the behavior from significant others, subjective norms, and beliefs in control over engaging in the behavior, or perceived behavioral control ${ }^{5}$. Behavioral intentions are proposed as the most proximal determinant of behavior. Intentions represent an individuals' strength of motivation and the effort an individual is prepared to invest in performing the coping behavior in future (c.f., Chatzisarantis et al., 2004). Intentions are conceptualized as a mediator of the effects of attitudes, subjective norms, and perceived control on behavior. The theory has been applied extensively to predict health-related

\footnotetext{
${ }^{4}$ Attitudes are summary of individuals' outcome expectancies with respect to a target behavior and encompass a number of related constructs from other social cognition theories such as costs and benefits in the health belief model (Becker, 1974), response costs and response benefits from protection motivation theory (Rogers, 1975), or outcome expectancies from the health action process approach (Schwarzer, 2008; Zhang et al., 2019). The attitude construct from the theory of planned behavior should, therefore, be considered representative of the multiple constructs that reflect outcome expectancies derived from different theories and models (Hagger \& Hamilton, 2020a; McMillan \& Conner, 2007).

${ }^{5}$ Parallels have been drawn between perceived behavioral control and self-efficacy beliefs (Ajzen, 1985).
} 
behavior in multiple behavioral contexts (Armitage \& Conner, 2001), including health (Hagger, Polet, et al., 2018; Hamilton et al., 2020; McEachan et al., 2011).

It is important to note that the constructs from the theory of planned behavior represent sets of beliefs. Based on Ajzen's original suggestions, the theory constructs may be operationalized as summary evaluative measures (e.g., attitude measures tapping positive or negative disposition toward the behavior, "performing coping behavior $\mathrm{X}$ is... pleasant/unpleasant, worthwhile/not worthwhile") or in terms of underlying behavioral outcome expectancies specific to the population and coping behavior under investigation that are derived from pilot elicitation surveys (e.g., items reflecting the likelihood of specific outcomes resulting from behavioral performance, such as whether it will be painful, embarrassing, effective in controlling symptoms; Ajzen, 1985). Similarly, subjective norms may reference 'the generalized other' or seek information about specific social agents such as family members, doctors or employers. Perceived behavioral control may refer to factors relating to objective control (e.g., accessibility of healthcare, costs of medication), or beliefs in capacity to manage or overcome barriers that make action difficult to perform (e.g., insufficient knowledge on how to perform health-promoting behaviors, medication side effects, perceived ability to cope with side effects, personal efficacy in talking to a physician or health professional about prognosis and outcomes), similar to self-efficacy beliefs.

Importantly, the theory is viewed as a flexible framework that can be augmented with additional belief-based predictors and has been the root of newly-developed integrated models of behavior (cf., Fishbein \& Ajzen, 2010; Hagger \& Chatzisarantis, 2009; Jacobs et al., 2011; Montaño \& Kasprzyk, 2015; Protogerou et al., 2018), including the common sense model (Hagger, Koch, et al., 2017). Orbell et al. (2006) first proposed an integration of the common sense model with constructs from the theory of planned behavior to test the simultaneous effects of 'beliefs about illness' and 'beliefs about behaviors' on coping 
procedures in patients invited to attend a colposcopy clinic. Participants were newly 'diagnosed' in the sense that they had just received an abnormal cervical screening result. Beliefs about behaviors and intentions were found to have the most pervasive effects on clinic attendance, but the cause, identity, and illness coherence representation dimensions alongside the planned behavior constructs were important in discriminating between those who attended their clinic appointments, those who had to be prompted, and those that failed to attend. Subsequent studies have adopted similar integrated approaches in the prediction of behaviors in multiple illness contexts (e.g., French et al., 2013; Hagger et al., 2019; Hagger et al., 2016; Hagger, Hardcastle, et al., 2018; Molloy et al., 2009). Overall, results have corroborated Orbell et al.'s findings with beliefs about behaviors tending to have stronger effects on adoption of coping behaviors, with effects of representations dimensions smaller by comparison (e.g., French et al., 2013; Orbell et al., 2006). So while it could be argued that a level of perceived threat (e.g., perceived serious consequences) is pre-requisite to motivate behavior change, it seems that beliefs about behaviors generally account the majority of the variance in coping behaviors when measured alongside illness representations (Hagger, Cameron, et al., 2020). Illness representations, on the other hand, may be important determinants of emotion-focused, avoidant-oriented coping procedures that do not involve participation in specific, treatment-focused behaviors, such as avoidance and emotion venting (Dempster et al., 2015; Hagger, Koch, et al., 2017).

Consistent with this research, we have integrated belief-based constructs regarding coping behavior from the theory of planned behavior in our extended version of the common sense model (see Figure 2). Attitudes, subjective norms, and perceived behavioral control are depicted as having independent effects on coping behaviors alongside illness representation dimensions. It is important to note that a focus on future performance of specific coping behaviors (e.g., medication adherence, appointment attendance) and procedures (e.g., 
cognitive reappraisal) likely to lead to adaptive outcomes is central to the extended model, consistent with the original conceptualization of the common sense model. This should be contrasted with the generic problem-focused coping procedures that have been the focus of much research applying the common sense model, and reflect generalized tendencies rather than specific behaviors. As a consequence, we refer to approach-oriented coping behaviors or procedures in the revised model and coping procedures aimed at managing or avoiding the negative emotional response arising from the health threat. Intentions are also included as a mediator of the effects of the beliefs on coping behaviors, consistent with theory.

A consistent observation in research applying the theory of planned behavior to predict health behavior is the relatively modest size of the relationship between intentions and behavior. Studies examining this intention-behavior 'gap' has revealed that while some individuals are effective in enacting their intentions, others, labelled 'inclined abstainers' or 'unsuccessful intenders', do not do so (Orbell \& Sheeran, 1998; Rhodes \& de Bruijn, 2013). One reason why individuals fail to act on their intentions is that they do not sufficiently specify the conditions or steps required to carry out the intended behavior. The common sense model and other 'action control' models (e.g., Gollwitzer \& Brandstätter, 1997; Schwarzer, 2008; Zhang et al., 2019) highlight the value of supplementing intentions with action plans - stated plans on when, where, and how the intended behavior should be performed - in facilitating intention enactment. Research has indicated that prompting people to form plans (see Hagger et al., 2012 for an example intervention) promotes behavioral enactment by improving recall of the intention and promoting greater efficiency in action control (Gollwitzer \& Brandstätter, 1997; Leventhal et al., 2016; Leventhal et al., 1965; Orbell et al., 1997). We have also included action planning as a moderator of relations between intentions and behavior in the extended model, consistent with the original model (see Figure 2). Action plans are inextricably linked with beliefs about the coping behavior, 
and should also, therefore, be correlated with the belief-based determinants of the coping behavior, namely attitudes, subjective norms, and perceived behavioral control.

Specifying the Model. A specific example of the integration of beliefs from the theory of planned behavior and common sense model as antecedents of coping behavior is presented in Figure 4. Coping behaviors aimed at managing the target illness is depicted as a function of cognitive representations of the illness (e.g., whether or not the illness will have serious consequences and is controllable) and social cognition beliefs about the behavior (e.g., whether or not the behavior is instrumental in producing desired outcomes, endorsed by significant others, and something the individual has the capacity to do). Both sets of beliefs are hypothesized to relate to the coping behavior mediated by intentions. Action planning is included as a moderator of the intention-behavior relationship. The relations outline the multiple pathways on which patients' decisions to engage in coping behaviors depend. Beliefs about illness and behavior are likely to have independent effects on individuals' intentions to select the coping behavior, and subsequent participation in the coping behavior, which in turn is expected to affect illness related outcomes.

In addition, consistent with the common sense model, cognitive and emotional illness representation dimensions may also predict coping behavior directly, unmediated by intentions. The direct effects may reflect more spontaneous, automatic associations between representations and performance of the coping behavior (Orbell \& Phillips, 2019). Cognitive representations are likely to predict behavior directly if the individual has a long history of using a particular coping behavior for the illness in question. In such cases, activation of the illness representation will lead to concomitant activation of the coping response, and fast, efficient enactment of the coping behavior with little conscious, intentional input (Henderson et al., 2009; Orbell \& Phillips, 2019). Similarly, emotional representations are also likely to affect behavior through a spontaneous pathway. This is consistent with previous research 
with the common sense model, and other social cognition models, in which decisions based on affect evoke reflexive behavioral responses that are often well-learned, habitual decisions (e.g., Conner et al., 2015). For example, emotional representations (e.g., beliefs that the illness will lead to negative emotional responses) may result in the fast and efficient activation of a reflexive coping response stored in associative memory that has been effective in dealing with the emotional upheaval in the past, like substance use or emotion venting. Again this pathway is more likely if the individual has performed the coping behavior in the past and it is represented as a viable coping response in their illness schema.

More broadly, the presence of direct effects of representation dimensions on coping behaviors unmediated by intentions effectively illustrates a boundary condition of both the common sense model and the theory of planned behavior. These social cognition approaches place considerable emphasis on constructs whose effects on action represent reasoned processes. This is contrasted with research that has recognized the importance of impulsive, non-conscious processes to action initiation and maintenance (Deutsch et al., 2017; Deutsch \& Strack, 2020; Hagger, 2016). Research has suggested that certain behaviors, and in certain contexts and conditions, are determined by constructs that represent these non-conscious processes. For example, studies have noted the consistent effect of constructs representing habit or implicit cognition on behavior in multiple health contexts (e.g., Hagger, 2019; Hagger, Trost, et al., 2017; Hamilton et al., 2017; Keatley et al., 2012; Orbell \& Verplanken, 2010). Within the common sense model, researchers have demonstrated how certain processes in the model, such as the link between illness-related stimuli and representations, or between illness and coping representations, are activated in an 'automatic' fashion (Henderson et al., 2009; Orbell et al., 2015). There have also been calls to recognize how such automatic processes can be capitalized upon to develop more effective behavioral interventions to promote adaptive coping (Hagger, 2016; Hagger, Cameron, et al., 2020; 
Orbell \& Phillips, 2019). However, to date, there is relatively little research examining effects of implicit cognition in the context of the common sense model and, given the excess emphasis on constructs that represent reasoned processing in the current research literature, represents a priority area for future investigation.

Moderation Effects. Consistent with original propositions of the common sense model, the extended model also formalizes important interactions between the antecedents of coping behaviors. Self-efficacy has been identified as an important moderator of effects of threat perceptions and emotional responses on coping behavior. Leventhal et al. (1980) proposed that the effects of fear are relatively short lived and seldom motivate change unless the individual has sufficient confidence to engage in a course of action to manage the threat, and view the response as efficacious in managing the threat. This corroborates research indicating that individuals are more likely to make an active response to a health threat when self- or response-efficacy are high (e.g., Orbell et al., 2017; Orbell et al., 2020; Peters et al., 2013). Perceived behavioral control and self-efficacy perceptions are, therefore, proposed to moderate the effects of cognitive and emotional representations on coping behavior, illustrated by the broken lines in Figure 4.

In addition, we propose that threat perceptions and emotional representations will moderate effects of intentions on coping procedures. Heightened threat and emotional responses to the illness may interfere with individuals' efforts to engage in approach-oriented coping procedures. Leventhal et al. (1980) suggest that when illnesses are perceived as highly threatening and accompanied by a heightened fear response, illness representations may interfere with decisions to engage in coping behaviors. Instead, individuals' efforts are more likely directed toward managing the arousal and emotional distress. This is illustrated by the broken lines of cognitive and emotional representations on the intention-coping behavior relationship in Figure 4. These effects may particularly be the case where perceived 
behavioral control is low, such that when perceived behavioral control is low, and threat and emotional responses are high, the individual will be less likely to enact their typical behavioral response.

\section{Beliefs about Treatment}

Patients' beliefs about treatment are also an important component of individuals' cognitive representation of illness (Leventhal et al., 1992). Treatment beliefs are expected to contribute to individuals' decisions to select a particular treatment or coping behavior and their level of compliance with their selected treatment. Measures based on the common sense model have been augmented to incorporate these beliefs, such as the treatment control dimension in the IPQ-R. This measure is restricted to beliefs that treatment (e.g., using a prophylactic, taking antibiotics, having an operation) will be effective in treating the condition (e.g., "treatment can control my condition"). However, researchers have sought to incorporate extended accounts of treatment beliefs within the common sense model (Horne et al., 2013; Horne et al., 1999; Phillips et al., 2014). In our extended model we have drawn from this research to include more comprehensive dimensions of treatment beliefs. In this research, treatments are typically specific coping behaviors such as taking medication or engaging in exercises to aid rehabilitation, recovery, and prevention of relapse (e.g., performance of physiotherapy rehabilitation exercises to aid recovery from joint surgery). Similarly, the content of the representation of these treatments are similar to expectancies for any behavioral coping response based on the social cognition approach.

At the forefront of research on treatment beliefs, are studies on beliefs about medication - a specific form of treatment beliefs expected to be related to medication adherence (Horne et al., 1999). According to Horne et al., medication adherence would also be a function of individuals' expectancies about the necessity and efficacy of specific medication in treating their particular illness or conditions, as well as generalized beliefs with 
respect to the harm and overuse of medication (e.g., concerns that medication might be unnecessary and potentially harmful). The beliefs about medication questionnaire (BMQ; Horne et al., 1999) was developed to measure the generalized and specific beliefs about medication. Research has demonstrated significant effects of BMQ dimensions on medication adherence independent of other illness representation dimensions. Specifically, necessity beliefs were positively associated, and concerns negatively related, to medication adherence (e.g., Byrne et al., 2005; Horne \& Weinman, 2002). Although the BMQ focuses on medication adherence as a special case of treatment beliefs, research could potentially extend the necessity and harms components to other types of treatment. Such research may extend the explanatory power of the treatment beliefs construct. For this reason we propose to include treatment beliefs as an additional, independent predictor of coping in the extended model (Figure 2).

It is important to note that while beliefs about behaviors, treatment beliefs, and illness representations may be correlated, as illustrated by the bidirectional arrows in Figure 2, there are clear conceptual distinctions in the sets of beliefs that underpin the attitude, subjective norm and perceived behavioral control constructs, and the illness beliefs from the common sense model, such as treatment control, personal control, and treatment beliefs. For example, a patient may believe that an operation could extend his or her life (treatment control), but also perceive personally negative outcomes associated with undergoing the operation (e.g., an inability to fulfill role obligations during recovery; holding an attitude that the procedure discomfort does not justify the possible outcome) that may or may not correspond with perceived expectations of others regarding actions taken to manage the illness or condition (subjective norms). Similarly, an individual might believe an oral medication to treat an illness is necessary (treatment beliefs), but possess low self-efficacy to adhere to the 
medication because, for example, they perceive the instructions for use to be too complex or that it is difficult to swallow (perceived behavioral control).

\section{Moderators of Effects of Representations on Coping}

The predictions of the common sense model are conditional on social, cultural, and ecological variables, some of which have been explored in previous research (e.g., Martin et al., 2003; Petrie \& Weinman, 2012). Potential moderators include objective characteristics of the illness (e.g., whether the illness is symptomatic or asymptomatic; Orbell et al., 2006; Orbell et al., 2008); personality traits and individual differences (e.g., optimism, perfectionism, negative affectivity; Karademas et al., 2011; Martin et al., 2003; McAndrew et al., 2014); and socio-structural variables (e.g., ethnicity, socio-economic status; Hagger \& Hamilton, 2020b; Schüz et al., 2017). It is important to note that these variables are only a small selection of the potential moderators of common sense model effects. Other moderators have also been proposed such as variables representing cultural and socio-ecological contexts (e.g., DeLongis \& Morstead, 2019; Leventhal et al., 1992). Furthermore, the proposed moderators may also impact other pathways in the model, such as relations between coping behaviors and some illness outcomes. For example, whether coping behaviors impact emotional outcomes (e.g., psychological well-being, distress) may be conditional on an individual's optimism or trait negative affectivity. So, the current moderator effects are intended to be illustrative of potential moderator effects in the model rather than definitive. In the next sections we illustrate how the effects these select variables moderate effects in the extended model, and how knowledge of these moderating effects may inform future theory and research.

\section{Illness Characteristics}

Illnesses with characteristic sets of symptoms that facilitate a good match of the representation with the illness prototype are likely to lead to strong effects of representation 
dimensions on coping procedure selection. This may be the case, for example, for illnesses such as celiac disease or conditions such as angina that have well-defined sets of symptoms known to the individual. This will also be dependent on level of experience with the illness and available information on effective management strategies, communicated by health professional or other sources of expert information. This should be contrasted with asymptomatic conditions (e.g., early-stage prostate cancer or glaucoma), where symptomatic information may be unavailable, or unreliable, as a prompt to coping procedure selection. For example, an angina sufferer with experience of the condition will likely have stronger effects of perceived consequences and control on approach-oriented coping procedures because they have good knowledge of the potential deleterious effects of the condition if left untreated, and will also have knowledge that the condition can be managed by taking their medication. In contrast, individuals with asymptomatic conditions would likely have weaker effects of illness representations on approach coping procedures as there are no direct prompts for the illness and associated coping procedure. If these pathways are confirmed empirically, they have clear implications for practice. The onus is on medical practitioners to provide individuals with asymptomatic conditions, or those with ambiguous or constantly changing symptoms, with clear information on means to prompt an appropriate coping response.

\section{Individual Differences}

We also propose individual differences as potential moderators of effects of representations on coping behaviors in the extended model. Previous research has revealed that individual differences moderate effects of representations on coping responses and illness outcomes. For example, Karademas et al. (2011) found that optimism moderated illness representation effects on outcomes in cardiac patients. More optimistic patients generally had stronger effects of treatment control, and weaker effects of consequences, timeline, and emotional representations, on adaptive outcomes (e.g., functioning, well-being). 
Similarly, Spence and Moss-Morris (2007) found that patients with irritable bowel syndrome who reported negative perfectionism tended to carry on with their lifestyle even in the face of mild symptoms, leading to symptom exacerbation until rest is unavoidable. This led to a cycle of pressing hard followed by rest; an 'all-or-nothing' pattern of behavior. For the same reason, individuals reporting negative perfectionism may also be at greater risk of exacerbating the symptoms of infectious diseases (e.g., COVID-19). Such individuals may be more likely to strive to return prematurely to full functionality in the face of potentially serious consequences, which may lead to cycles of illness exacerbation and necessity for treatment (e.g., repeated recurrence of COVID-19 infections or even multiple hospital readmissions). In such cases, perfectionism moderates the effect of serious consequences and personal control representations on performance of the coping response downwards.

Following these lines of research, trait negative affectivity, the generalized tendency to respond to illness stimuli signaling potentially serious consequences with high levels of negative affect, such as anxiety and worry, is likely to exacerbate tendencies to adopt coping procedures to deal with emotional discomfort, and detract from efforts to engage in approachoriented coping procedures. We illustrate this pattern in the specific example of the revised common sense model in Figure 5. Here trait negative affectivity has negative moderating effects, illustrated by the broken arrows, on relations of perceived consequences and personal control representation dimensions on problem focused coping. Similarly, negative affectivity has positive moderating effects on relations between perceived consequences and emotional representations on emotion-focused and avoidant-oriented coping. Individuals high in trait negative affectivity are more likely to prioritize coping procedures to minimize the emotional response, and tend to dampen processes leading to the adoption of approach-oriented coping procedures. We look to future research to empirically confirm the moderating effect of this trait on model effects. 


\section{Emotional Representations}

Consistent with Leventhal et al.'s (1980) proposal that cognitive and emotional representations represent parallel and interactive pathways to coping responses, emotional representations are also a candidate moderator of effects of cognitive representations in the model. While cognitive and emotional representations determine selection of coping procedure independently, Leventhal et al. indicated occasions where the two pathways may interact. Illness-related stimuli indicating a health threat may evoke a fear or anxious response. If particularly marked, the emotional response may lead to the individual prioritizing a coping response aimed at mitigating negative emotions (e.g., expressing emotions) instead of an approach-oriented coping behavior. In addition, the emotional response may be relatively short lived, particularly if coping procedures aimed at reducing negative affect mitigate the discordance. As a consequence, fear may not be sufficient to evoke an approach-oriented coping response. However, when perceived control or selfefficacy over a salient approach-oriented coping response is high, emotional representations may lead to engagement in the coping behavior. This is consistent with research demonstrating the interactive effect of emotional representations on the effects of perceived control on coping. This pattern of effects is depicted in Figure 6, with broken lines illustrating the interaction effects.

Similarly, emotional representations may determine whether perceived consequences will motivate selection of a coping response aimed at managing emotions alone rather than one that is approach-oriented. When emotional representations are high, threat perceptions like perceived consequences are more likely to motivate adoption of coping procedures aimed at managing the emotional upheaval. In contrast, lower emotional representations may mean that individuals are less likely to be preoccupied with managing negative affect, in which case threat perceptions may be more likely to motivate selection of a coping behavior rather 
than an avoidant coping response. Thus emotional representations may determine the type of coping procedure selected. While interactions between cognitive and emotional processes in the common sense model have been widely implied in theoretical accounts, these effects have not, to date, been formally operationalized or tested empirically. Our formalization of these predictions in our extended model provide some specific testable hypotheses relating to the potential moderation effects from the original model, and testing these hypotheses should be a priority in future research.

When evaluating the role of emotional representations in the model, it is important to note the conceptual distinction between emotional representations (e.g., "cancer is a very scary disease") and emotional states (e.g., "I am scared"). Leventhal et al. (1980) made this distinction in the model, and measures of emotional representations, such as those introduced in the IPQ-R, represent individuals reflections on their emotional responses to the illness, which should be distinct from generalized emotional states. However, making a distinction between these emotional responses empirically has proven difficult, with high correlations noted between emotional response and emotional representation measures (e.g., Hagger \& Orbell, 2006). This presents considerable challenges for researchers aiming to test the distinct influences of emotional representations attributable to an illness and overall emotional states. This may necessitate measurement studies to identify measures of emotional representations that achieve discriminant and criterion validity from emotional states within the model, and remains an important avenue for future studies.

\section{Socio-Structural Variables}

Leventhal et al. $(2005 ; 1980)$ explicitly outline that the self-regulatory processes involved in individuals' coping with illness would be impacted by, and depend on, the sociocultural context of the individual. Individuals' illness representations are likely to be shaped by their social (e.g., sharing illness experiences with others, having contact with others with 
the illness), socio-ecological (e.g., experiences with the healthcare system, treatment availability), and cultural (e.g., group norms within ethnic groups) contexts. These factors may also impact their selection and representation of coping behaviors, and moderate the effects of representation dimensions on coping and outcomes. These predictions are in keeping with studies that have provided accounts of how socio-structural variables function within social cognition models, beyond mere control for their influence (e.g., Godin et al., 2010; Hagger \& Hamilton, 2020b; McKinley et al., 2020; Orbell et al., 2006; Orbell et al., 2017; Schüz et al., 2020; Schüz et al., 2017). Although we do not formally specify the role of socio-structural variables in the extended model, we advocate future mechanistic tests of their effects. To illustrate, the effect of consequences and perceived control representation dimensions on coping behavior may be moderated by socioeconomic status. Individuals with lack of access to healthcare or expensive medication may refrain from selecting an approachfocused coping behavior (e.g., attending medical appointments, taking medication) in response to perceiving their illness will have serious consequences. Similarly, individuals from disadvantaged or underserved communities may perceive they have lower personal control over their illness and may be less likely engage in an adaptive coping behavior as a consequence. Including analyses examining effects of these variables would advance knowledge on the broader impact of social structures within the model, and should be a priority agendum for future research.

\section{Conclusion}

Effective self-regulation of health threats is fundamental to maintaining good health, optimal functioning, and, ultimately, survival (Hagger, 2010). The common sense model provides a framework of understanding how individuals process, respond, and manage health threats. We have proposed an extended version of the common sense model of illness selfregulation. Our extended model formally operationalizes important ancillary processes in the 
original model, and introduces additional constructs that provide more comprehensive explanations of relations between lay representations of health threats, coping responses, and illness outcomes. Our suggestions include (a) formal specification of the hypothesized mediation of the effects of representations on illness-related outcomes by coping procedures; (b) specification of the process by which stimuli may activate illness representations stored schematically and coping-related information stored in associative memory; (c) explicitly stating and modeling effects of beliefs about coping behaviors and treatment beliefs in the prediction of coping and illness outcomes parallel to the cognitive and emotional illness representations; and (d) specifying moderators of model effects such as illness type, individual differences (e.g., optimism, perfectionism, trait negative affectivity), emotional representations, and socio-structural variables.

We provide hypotheses and evidence to indicate that illness representations are schematic in nature, are activated on presentation of specific illness stimuli, and that typical coping-related information is activated alongside the representation. We highlight the importance of specifying of mediation effects in the extended model, particularly a consideration of the effects of threat representations in motivating approach-oriented coping behaviors and avoidant-oriented coping procedures. We also specify the importance of distinguishing between illness representations, as captured by measures such as the IPQ-R, and constructs that represent beliefs about performing specific coping behaviors in future, represented by constructs from the theory of planned behavior. Such distinctions enable specification of formal hypotheses regarding the effects of each set of beliefs, and identifying their relative contribution to the prediction of coping behavior and illness outcomes. It also permits elucidation of potential mechanisms, such as the extent to which effects of the belief constructs on coping behavior are mediated by intention to perform the behavior, or impact coping directly. In addition, we propose the importance of specifying and testing conditions 
that magnify or diminish model pathways, particularly selection of coping procedures in response to threating representations, such as presence of strong emotional responses, trait negative affectivity, and perfectionism. We have also advocated consideration of sociostructural variables in the model, and how they may be implicated in representation and coping procedures beyond merely controlling for their effects. We have proposed suggestions for future research, such as adoption of longitudinal and experimental designs to test hypothesized effects, and practice, such as targeting change in beliefs about behaviors and illness beliefs depending on the type of coping behavior.

Overall, we have provided formal specification of how the additional constructs and processes fit within the common sense model, and identified sets of hypotheses that can be tested in empirical research guided by the revised model. We expect our model to set an agenda for future research examining the interface between common sense representations of health threats, coping responses, and illness status and health-related outcomes. 


\section{References}

Affleck, G., Tennen, H., Croog, S., \& Levine, S. (1987). Causal attribution, perceived control, and recovery from a heart attack. Journal of Social and Clinical Psychology, 5(3), 339-355. https://doi.org/10.1521/jscp.1987.5.3.339

Ahluwalia, M., Hughes, A. M., McCracken, L. M., \& Chilcot, J. (2017). A pilot study examining the effects of priming headache illness schema on attentional engagement towards pain relief medication, in those with high and low medication treatment beliefs. Psychology, Health \& Medicine, 22(7), 808-813. https://doi.org/10.1080/13548506.2017.1281979

Ajzen, I. (1985). From intentions to actions: A theory of planned behavior. In J. Kuhl \& J. Beckmann (Eds.), Action-control: From cognition to behavior (pp. 11-39). Springer. https://doi.org/10.1007/978-3-642-69746-3_2

Ajzen, I., \& Kruglanski, A. W. (2019). Reasoned action in the service of goal pursuit. Psychological Review, 126(5), 774-786. https://doi.org/10.1037/rev0000155

Anagnostopoulos, F., Dimitrakaki, C., Fitzsimmons, D., Potamianos, G., Niakas, D., \& Tountas, Y. (2012). Health beliefs and illness perceptions as related to mammography uptake in randomly selected women in Greece. Journal of Clinical Psychology in Medical Settings, 19(2), 147-164. https://doi.org/10.1007/s10880-011-9272-1

Armitage, C. J., \& Conner, M. (2001). Efficacy of the theory of planned behaviour: A metaanalytic review. British Journal of Social Psychology, 40(4), 471-499. https://doi.org/10.1348/014466601164939

Bandura, A. (1986). Social foundations of thought and action: A social-cognitive theory. Prentice-Hall.

Baumann, L. J., Cameron, L. D., Zimmerman, R. S., \& Leventhal, H. (1989). Illness representations and matching labels with symptoms. Health Psychology, 8(4), 449-469. https://doi.org/10.1037/0278-6133.8.4.449

Becker, M. (1974). The health belief model and sick role behavior. Health Education Monographs, 2(4), 409-419. https://doi.org/10.1177/109019817400200407

Benyamini, Y., Gozlan, M., \& Kokia, E. (2004). On the self-regulation of a health threat: Cognitions, coping, and emotions in women undergoing treatment for infertility. Cognitive Therapy and Research, 28(5), 557-592. https://doi.org/10.1023/B:COTR.0000045566.97966.22

Benyamini, Y., \& Karademas, E. C. (2019). Introduction to the special issue on the common sense model of self-regulation. Health Psychology Review, 13(4), 373-377. https://doi.org/10.1080/17437199.2019.1644189

Bishop, G. D., \& Converse, S. A. (1986). Illness representations: A prototype approach. Health Psychology, 5(2), 95-114. https://doi.org/10.1037/0278-6133.5.2.95

Brewer, N. T., Chapman, G. B., Brownlee, S., \& Leventhal, E. (2002). Cholesterol control, medication adherence and illness cognition. British Journal of Health Psychology, 7(4), 433-447. https://doi.org/10.1348/135910702320645408

Burke, L. E., Shiffman, S., Music, E., Styn, M. A., Kriska, A., Smailagic, A., Siewiorek, D., Ewing, L. J., Chasens, E., French, B., Mancino, J., Mendez, D., Strollo, P., \& Rathbun, S. L. (2017). Ecological momentary assessment in behavioral research: Addressing technological and human participant challenges. Journal of Medical Internet Research, 19(3), e77-e77. https://doi.org/10.2196/jmir.7138

Byrne, M., Walsh, J., \& Murphy, A. W. (2005). Secondary prevention of coronary heart disease: Patient beliefs and health-related behaviour. Journal of Psychosomatic Research, 58(5), 403-415. https://doi.org/10.1016/j.jpsychores.2004.11.010 
Cameron, L. D., Fleszar-Pavlović, S., \& Khachikian, T. (2020). Changing behavior using the common sense model of self-regulation. In M. S. Hagger, L. D. Cameron, K. Hamilton, N. Hankonen \& T. Lintunen (Eds.), The handbook of behavior change (pp. 60-76).

Cambridge University Press. https://doi.org/10.1017/97811086773180.005

Cameron, L. D., Leventhal, H., \& Love, R. R. (1998). Trait anxiety, symptom perceptions, and illness-related responses among women with breast cancer in remission during a tamoxifen clinical trial. Health Psychology, 17(5), 459-469.

https://doi.org/10.1037/0278-6133.17.5.459

Cameron, L. D., Petrie, K. J., Ellis, C. J., Buick, D., \& Weinman, J. A. (2005). Trait negativity and responses to a health education intervention for myocardial infarction patients. Psychology and Health., 20(1), 1-18. https://doi.org/10.1080/08870440412331300011

Carver, C. S., Scheier, M. F., \& Weintraub, J. K. (1989). Assessing coping strategies: A theoretically based approach. Journal of Personality and Social Psychology, 56(2), 267-283. https://doi.org/10.1037//0022-3514.56.2.267

Chatzisarantis, N. L. D., Hagger, M. S., Smith, B., \& Phoenix, C. (2004). The influences of continuation intentions on the execution of social behaviour within the theory of planned behaviour. British Journal of Social Psychology, 43(4), 551-583. https://doi.org/10.1348/0144666042565399

Chilcot, J., Lee, E., Tylee, A., Brown, J., Weinman, J., Hotopf, M., \& Palacios, J. E. (2020). Distinct distress symptom trajectories over 3 years are associated with baseline illness perceptions in individuals with coronary heart disease. Annals of Behavioral Medicine, 54(5), 374-379. https://doi.org/10.1093/abm/kaz054

Clatworthy, J., Hankins, M., Buick, D., Weinman, J., \& Horne, R. (2007). Cluster analysis in illness perception research: A Monte Carlo study to identify the most appropriate method. Psychology \& Health, 22(2), 123-142. https://doi.org/10.1080/14768320600774496

Conner, M. T., McEachan, R., Taylor, N., O'Hara, J., \& Lawton, R. (2015). Role of affective attitudes and anticipated affective reactions in predicting health behaviors. Health Psychology, 34(6), 642-652. https://doi.org/10.1037/hea0000143

Crawshaw, J., Rimington, H., Weinman, J., \& Chilcot, J. (2015). Illness perception profiles and their association with 10-year survival following cardiac valve replacement. Annals of Behavioral Medicine, 49(5), 769-775. https://doi.org/10.1007/s12160-015-9695-2

Croyle, R. T., \& Jemmott, J. B. (1991). Psychological reactions to risk factor testing. In J. A. Skelton \& R. T. Croyle (Eds.), Mental representation in health and illness (pp. 85-107). Springer-Verlag.

DeLongis, A., \& Morstead, T. (2019). Bringing the social context into research using the common sense model. Health Psychology Review, 13(4), 481-483. https://doi.org/10.1080/17437199.2019.1652107

Dempster, M., Howell, D., \& McCorry, N. K. (2015). Illness perceptions and coping in physical health conditions: A meta-analysis. Journal of Psychosomatic Research, 79(6), 506-513. https://doi.org/10.1016/j.jpsychores.2015.10.006

Deutsch, R., Gawronski, B., \& Hofmann, W. (Eds.). (2017). Reflective and impulsive determinants of human behavior. Psychology Press.

Deutsch, R., \& Strack, F. (2020). Changing behavior using the reflective-impulsive model. In M. S. Hagger, L. D. Cameron, K. Hamilton, N. Hankonen \& T. Lintunen (Eds.), Handbook of Behavior Change (pp. 164-177). Cambridge University Press. https://doi.org/10.1017/97811086773180.012 
Durazo, A., \& Cameron, L. D. (2019). Representations of cancer recurrence risk, recurrence worry, and health-protective behaviours: An elaborated, systematic review. Health Psychology Review, 13(4), 447-476. https://doi.org/10.1080/17437199.2019.1618725

Evans, D., \& Norman, P. (2009). lllness representations, coping and psychological adjustment to Parkinson's disease. Psychology \& Health, 24(10), 1181-1196. https://doi.org/10.1080/08870440802398188

Fishbein, M., \& Ajzen, I. (2010). Predicting and changing behavior: The reasoned action approach. Psychology Press. https://doi.org/10.4324/9780203838020

Folkman, S., \& Lazarus, R. S. (1988). Ways of coping questionnaire: Research edition. Consulting Psychologists Press Inc.

French, D. P., Wade, A. N., \& Farmer, A. J. (2013). Predicting self-care behaviours of patients with type 2 diabetes: The importance of beliefs about behaviour, not just beliefs about illness. Journal of Psychosomatic Research, 74(4), 327-333. https://doi.org/10.1016/j.jpsychores.2012.12.008

French, D. P., \& Weinman, J. (2008). Current issues and new directions in Psychology and Health: Assessing illness perceptions: Beyond the IPQ. Psychology and Health, 23(1), 5-9. https://doi.org/10.1080/08870440701616714

Godin, G., Sheeran, P., Conner, M., Belanger-Gravel, A., Cecilia, M., Gallani, B. J., \& Nolin, B. (2010). Social structure, social cognition, and physical activity: A test of four models. British Journal of Health Psychology, 15(1), 79-95. https://doi.org/10.1348/135910709x429901

Gollwitzer, P. M., \& Brandstätter, V. (1997). Implementation intentions and effective goal pursuit. Journal of Personality and Social Psychology, 73(1), 186-199. https://doi.org/10.1037/0022-3514.73.1.186

Hagger, M. S. (2009). Theoretical integration in health psychology: Unifying ideas and complimentary explanations. British Journal of Health Psychology, 14(2), 189-194. https://doi.org/10.1348/135910708X397034

Hagger, M. S. (2010). Self-regulation: An important construct in health psychology research and practice. Health Psychology Review, 4(2), 57-65.

https://doi.org/10.1080/17437199.2010.503594

Hagger, M. S. (2016). Non-conscious processes and dual-process theories in health psychology. Health Psychology Review, 10(4), 375-380. https://doi.org/10.1080/17437199.2016.1244647

Hagger, M. S. (2019). Habit and physical activity: Theoretical advances, practical implications, and agenda for future research. Psychology of Sport and Exercise, 42, 118-129. https://doi.org/10.1016/j.psychsport.2018.12.007

Hagger, M. S., Cameron, L. D., Hamilton, K., Hankonen, N., \& Lintunen, T. (Eds.). (2020). The handbook of behavior change. Cambridge University Press. https://doi.org/10.1017/9781108677318

Hagger, M. S., \& Chatzisarantis, N. L. D. (2009). Integrating the theory of planned behaviour and self-determination theory in health behaviour: A meta-analysis. British Journal of Health Psychology, 14(2), 275-302. https://doi.org/10.1348/135910708X373959

Hagger, M. S., Chatzisarantis, N. L. D., Griffin, M., \& Thatcher, J. (2005). Injury representations, coping, emotions, and functional outcomes in athletes with sportrelated injuries: A test of self-regulation theory. Journal of Applied Social Psychology, 35(11), 2345-2374. https://doi.org/10.1111/j.1559-1816.2005.tb02106.x

Hagger, M. S., \& Hamilton, K. (2020a). Changing behavior using integrated theories. In M. S. Hagger, L. D. Cameron, K. Hamilton, N. Hankonen \& T. Lintunen (Eds.), The Handbook of Behavior Change (pp. 208-224). Cambridge University Press. https://doi.org/10.1017/97811086773180.015 
Hagger, M. S., \& Hamilton, K. (2020b). Effects of socio-structural variables in the theory of planned behavior: A mediation model in multiple samples and behaviors. Psychology \& Health. https://doi.org/10.1080/08870446.2020.1784420

Hagger, M. S., Hamilton, K., Hardcastle, S. J., Hu, M., Kwok, S., Lin, J., Nawawi, H. M., Pang, J., Santos, R. D., Soran, H., Su, T.-C., Tomlinson, B., \& Watts, G. F. (2019). Predicting intention to participate in self-management behaviors in patients with familial hypercholesterolemia: A cross-national study. Social Science \& Medicine, 242, 112591. https://doi.org/10.1016/j.socscimed.2019.112591

Hagger, M. S., Hardcastle, S. J., Hingley, C., Strickland, E., Pang, J., \& Watts, G. F. (2016). Predicting self-management behaviors in familial hypercholesterolemia using an integrated theoretical model: The impact of beliefs about illnesses and beliefs about behaviors. International Journal of Behavioral Medicine, 23(3), 282-294. https://doi.org/10.1007/s12529-015-9531-X

Hagger, M. S., Hardcastle, S. J., Hu, M., Kwok, S., Lin, J., Nawawi, H. M., Pang, J., Santos, R. D., Soran, H., Su, T.-C., Tomlinson, B., \& Watts, G. F. (2018). Effects of medication, treatment, and behavioral beliefs on intentions to take medication in patients with familial hypercholesterolemia. Atherosclerosis, 277, 493-501. https://doi.org/10.1016/j.atherosclerosis.2018.06.010

Hagger, M. S., Koch, S., Chatzisarantis, N. L. D., \& Orbell, S. (2017). The common-sense model of self-regulation: Meta-analysis and test of a process model. Psychological Bulletin, 143(11), 1117-1154. https://doi.org/10.1037/bul0000118

Hagger, M. S., Lonsdale, A., Koka, A., Hein, V., Pasi, H., Lintunen, T., \& Chatzisarantis, N. L. D. (2012). An intervention to reduce alcohol consumption in undergraduate students using implementation intentions and mental simulations: A cross-national study. International Journal of Behavioral Medicine, 19(1), 82-96. https://doi.org/10.1007/s12529-011-9163-8

Hagger, M. S., Moyers, S., McAnally, K., \& McKinley, L. E. (2020). Known knowns and known unknowns on behavior change interventions and mechanisms of action. Health Psychology Review, 14(1), 199-212. https://doi.org/10.1080/17437199.2020.1719184

Hagger, M. S., \& Orbell, S. (2003). A meta-analytic review of the common-sense model of illness representations. Psychology and Health, 18(2), 141-184. https://doi.org/10.1080/088704403100081321

Hagger, M. S., \& Orbell, S. (2006). Illness representation and emotion in people with abnormal screening results. Psychology and Health, 21(2), 183-209. https://doi.org/10.1080/14768320500223339

Hagger, M. S., Polet, J., \& Lintunen, T. (2018). The reasoned action approach applied to health behavior: Role of past behavior and test of some key moderators using metaanalytic structural equation modeling. Social Science \& Medicine, 213, 85-94. https://doi.org/10.1016/j.socscimed.2018.07.038

Hagger, M. S., Trost, N., Keech, J., Chan, D. K. C., \& Hamilton, K. (2017). Predicting sugar consumption: Application of an integrated dual-process, dual-phase model. Appetite, 116, 147-156. https://doi.org/10.1016/j.appet.2017.04.032

Hamilton, K., Kirkpatrick, A., Rebar, A., \& Hagger, M. S. (2017). Child sun safety: Application of an integrated behavior change model. Health Psychology, 36(9), 916926. https://doi.org/10.1037/hea0000533

Hamilton, K., van Dongen, A., \& Hagger, M. S. (2020). An extended theory of planned behavior for parent-for-child health behaviors: A meta-analysis. Health Psychology, 39(10), 863-878. https://doi.org/10.1037/hea0000940 
Hampson, S. E., Glasgow, R. E., \& Foster, L. S. (1995). Personal models of diabetes among older adults: Relationship to self-management and other variables. The Diabetes Educator, 21(4), 300-306. https://doi.org/10.1177/014572179502100407

Hampson, S. E., Glasgow, R. E., \& Toobert, D. J. (1990). Personal models of diabetes and their relations to self-care activities. Health Psychology, 9(5), 632-646. https://doi.org/10.1037/0278-6133.9.5.632

Hayes, A. F. (2018). Introduction to mediation, moderation, and conditional process analysis: A regression-based approach (2nd ed.). Guildford Press.

Heerema-Poelman, A., Stuive, I., \& Wempe, J. B. (2011). Adherence to a maintenance exercise program 1 year after pulmonary rehabilitation: what are the predictors of dropout? Journal of Cardiopulmonary Rehabilitative Prevention, 33(6), 419-426. https://doi.org/10.1097/HCR.0b013e3182a5274a

Heijmans, M. (1999). The role of patients' illness representations in coping and functioning with Addison's disease. British Journal of Health Psychology, 4(2), 137-149. https://doi.org/10.1348/135910799168533

Henderson, C. J., Hagger, M. S., \& Orbell, S. (2007). Does priming a specific illness schema result in an attentional information-processing bias for specific illnesses? Health Psychology, 26(2), 165-173. https://doi.org/10.1037/0278-6133.26.2.165

Henderson, C. J., Orbell, S., \& Hagger, M. S. (2009). Illness schema activation and attentional bias to coping procedures. Health Psychology, 28(1), 101-107. https://doi.org/10.1037/a0013690

Hobro, N., Weinman, J., \& Hankins, M. (2004). Using the self-regulatory model to cluster chronic pain patients: The first step towards identifying relevant treatments? PAIN, 108(3), 276-283. https://doi.org/10.1016/j.pain.2003.12.027

Hofmann, W., \& Kotabe, H. (2012). A general model of preventive and interventive selfcontrol. Social and Personality Psychology Compass, 6(10), 707-722. https://doi.org/10.1111/j.1751-9004.2012.00461.x

Horne, R., Chapman, S. C. E., Parham, R., Freemantle, N., Forbes, A., \& Cooper, V. (2013). Understanding patients' adherence-related beliefs about medicines prescribed for longterm conditions: A meta-analytic review of the necessity-concerns framework. PLoS ONE, 8(12), e80633. https://doi.org/10.1371/journal.pone.0080633

Horne, R., \& Weinman, J. (1998). Predicting treatment adherence: An overview of theoretical models. In L. B. Myers \& K. Midence (Eds.), Adherence to treatment in medical conditions (pp. 25-50). Hardwood Academic Publishers.

Horne, R., \& Weinman, J. (2002). Self-regulation and self-management in asthma: Exploring the role of illness perceptions and treatment beliefs in explaining non-adherence to preventer medication. Psychology \& Health, 17(1), 17-32. https://doi.org/10.1080/08870440290001502

Horne, R., Weinman, J., \& Hankins, M. (1999). The beliefs about medicines questionnaire: The development and evaluation of a new method for assessing the cognitive representation of medication. Psychology and Health, 14(1), 1-24. https://doi.org/10.1080/08870449908407311

Hoving, J. L., Van Der Meer, M., Volkova, A. Y., \& Frings-Dresen, M. H. W. (2010). Illness perceptions and work participation: A systematic review. International Archives of Occupational and Environmental Health, 83(6), 595-605. https://doi.org/10.1007/s00420-010-0506-6

Hudson, J. L., Bundy, C., Coventry, P. A., \& Dickens, C. (2014). Exploring the relationship between cognitive illness representations and poor emotional health and their combined association with diabetes self-care. A systematic review with meta-analysis. Journal of 
Psychosomatic Research, 76(4), 265-274.

https://doi.org/10.1016/i.jpsychores.2014.02.004

Jacobs, N., Hagger, M. S., Streukens, S., De Bourdeaudhuij, I., \& Claes, N. (2011). Testing an integrated model of the theory of planned behaviour and self-determination theory for different energy-balance related behaviours and intervention intensities. British Journal of Health Psychology, 16(1), 113-134. https://doi.org/10.1348/135910710X519305

Johnson, B. T., \& Acabchuk, R. L. (2018). What are the keys to a longer, happier life? Answers from five decades of health psychology research. Social Science \& Medicine, 196, 218-226. https://doi.org/10.1016/j.socscimed.2017.11.001

Karademas, E. C. (2012). Conditional indirect relations of cardiac patients' subjective health to optimism through illness representations: A self-regulation circuit. Journal of Health Psychology, 17(1), 36-45. https://doi.org/10.1177/1359105311405554

Karademas, E. C., Kynigopoulou, E., Aghathangelou, E., \& Anestis, D. (2011). The relation of illness representations to the 'end-stage' appraisal of outcomes through health status, and the moderating role of optimism. Psychology \& Health, 26(5), 567-583. https://doi.org/10.1080/08870441003653488

Keatley, D. A., Clarke, D. D., \& Hagger, M. S. (2012). Investigating the predictive validity of implicit and explicit measures of motivation on condom use, physical activity, and healthy eating. Psychology and Health, 27(5), 550-569. https://doi.org/10.1080/08870446.2011.605451

Lau, R. R., \& Hartman, K. A. (1983). Common sense representations of common illnesses. Health Psychology, 2(2), 167-185. https://doi.org/10.1037/0278-6133.2.2.167

Lazarus, R. S. (1991). Progress on a cognitive-motivational-relational theory of emotion. American Psychologist, 46(8), 819-834. https://doi.org/10.1037/0003-066X.46.8.819

Leventhal, H., Cameron, L. D., Leventhal, E. A., \& Ozakinci, G. (2005). Do messages from your body, your friends, your doctor, or the media shape your health behavior? In T. Brock \& M. Green (Eds.), Persuasion, Psychological Insights and Perspectives (pp. 195-224). Sage.

Leventhal, H., Diefenbach, M. A., \& Leventhal, E. A. (1992). Illness cognition: Using common sense to understand treatment adherence and affect cognition interactions. Cognitive Therapy and Research, 16(2), 143-163. https://doi.org/10.1007/BF01173486

Leventhal, H., Leventhal, E., \& Contrada, R. J. (1998). Self-regulation, health, and behavior: A perceptual-cognitive approach. Psychology and Health, 13(4), 717-734. https://doi.org/10.1080/08870449808407425

Leventhal, H., Leventhal, E. A., \& Breland, J. Y. (2011). Cognitive science speaks to the "common sense" of chronic illness management. Annals of Behavioral Medicine, 41(2), 152-163. https://doi.org/10.1007/s12160-010-9246-9

Leventhal, H., Leventhal, E. A., \& Cameron, L. D. (2001). Representations, procedures, and affect in self-regulation: A perceptual-cognitive model. In A. Baum, T. A. Revenson \& J. E. Singer (Eds.), Handbook of Health Psychology (pp. 19-48). Erlbaum.

Leventhal, H., Meyer, D., \& Nerenz, D. (1980). The common sense model of illness danger. In S. Rachman (Ed.), Medical Psychology (Vol. II, pp. 7-30). Pergamon Press.

Leventhal, H., Phillips, L. A., \& Burns, E. (2016). The common-sense model of selfregulation (CSM): A dynamic framework for understanding illness self-management. Journal of Behavioral Medicine, 39(6), 935-946. https://doi.org/10.1007/s10865-0169782-2

Leventhal, H., Singer, R., \& Jones, S. (1965). Effects of fear and specificity of recommendation upon attitudes and behavior. Journal of Personality and Social Psychology, 2(1), 20-29. https://doi.org/10.1037/h0022089 
Leventhal, H., Weinman, J., Leventhal, E. A., \& Phillips, L. A. (2008). Health psychology: The search for pathways between behavior and health. Annual Review of Psychology, 59, 477-505. https://doi.org/10.1146/annurev.psych.59.103006.093643

Linz, D., Penrod, S., \& Leventhal, H. (1982). Cognitive organisation of disease among laypersons. Paper presented at the 20th International Congress of Applied Psychology, Edinburgh, Scotland, July 15-31.

Martin, R., Rothrock, N., Leventhal, H., \& Leventhal, E. (2003). Common sense models of illness: Implications for symptom perception and health-related behaviors. In J. Suls \& K. A. Wallston (Eds.), Social Psychological Foundations of Health and Illness (pp. 199-225). Blackwell Publishing Ltd. https://doi.org/10.1002/9780470753552.ch8

Mc Sharry, J., Moss-Morris, R., \& Kendrick, T. (2011). Illness perceptions and glycaemic control in diabetes: A systematic review with meta-analysis. Diabetic Medicine, 28(11), 1300-1310. https://doi.org/10.1111/j.1464-5491.2011.03298.x

McAndrew, L. M., Mora, P. A., Quigley, K. S., Leventhal, E. A., \& Leventhal, H. (2014). Using the common sense model of self-regulation to understand the relationship between symptom reporting and trait negative affect. International Journal of Behavioral Medicine, 21(6), 989-994. https://doi.org/10.1007/s12529-013-9372-4

McDonald, S., Quinn, F., Vieira, R., O’Brien, N., White, M., Johnston, D. W., \& Sniehotta, F. F. (2017). The state of the art and future opportunities for using longitudinal n-of-1 methods in health behaviour research: A systematic literature overview. Health Psychology Review, 11(4), 307-323. https://doi.org/10.1080/17437199.2017.1316672

McEachan, R. R. C., Conner, M. T., Taylor, N., \& Lawton, R. J. (2011). Prospective prediction of health-related behaviors with the theory of planned behavior: A metaanalysis. Health Psychology Review, 5(2), 97-144. https://doi.org/10.1080/17437199.2010.521684

McKinley, L. E., McAnally, K., Moyers, S., \& Hagger, M. S. (2020). Behavioral health theories, equity, and disparities in global health: A basic process model. In R. Haring, I. Kickbusch, D. Ganten \& M. R. Moeti (Eds.), Handbook of Global Health. Springer Nature. https://doi.org/10.1007/978-3-030-05325-3_58-1

McMillan, B., \& Conner, M. (2007). Health cognition assessment. In A. B. S. Ayers, C. McManus, S. Newman, K. Wallston, J. Weinman, \& R. West (Ed.), Cambridge Handbook of Psychology, Health and Medicine (2nd ed., pp. 260-266). Cambridge University Press.

Meyer, D., Leventhal, H., \& Gutmann, M. (1985). Common-sense models of illness: The example of hypertension. Health Psychology, 4(2), 115-135.

https://doi.org/10.1037/0278-6133.4.2.115

Molloy, G. J., Sniehotta, F. F., \& Johnston, M. (2009). Two alternative models of health behaviour and recovery from activity limitations due to acute injury: A prospective study. Psychology \& Health, 24(3), 271-285. https://doi.org/10.1080/08870440701684548

Montaño, D. E., \& Kasprzyk, D. (2015). Theory of reasoned action, theory of planned behavior, and the integrated behavioral model. In K. Glanz, B. K. Rimer \& K. Viswanath (Eds.), Health behavior and health education: Theory, research, and practice (5th ed., pp. 95-124). Jossey-Bass.

Moss-Morris, R. (2013). Adjusting to chronic illness: Time for a unified theory. British Journal of Health Psychology, 18(4), 681-686. https://doi.org/10.1111/bjhp.12072

Moss-Morris, R., Spence, M. J., \& Hou, R. (2011). The pathway from glandular fever to chronic fatigue syndrome: Can the cognitive behavioural model provide the map? Psychological Medicine, 41(5), 1099-1107. https://doi.org/10.1017/s003329171000139x 
Moss-Morris, R., Weinman, J. A., Petrie, K. J., Horne, R., Cameron, L. D., \& Buick, L. (2002). The revised illness perception questionnaire (IPQ-R). Psychology and Health, 17(1), 1-16. https://doi.org/10.1080/08870440290001494

Norton, S., Hughes, L. D., Chilcot, J., Sacker, A., van Os, S., Young, A., \& Done, J. (2014). Negative and positive illness representations of rheumatoid arthritis: A latent profile analysis. Journal of Behavioral Medicine, 37(3), 524-532. https://doi.org/10.1007/s10865-013-9506-9

Orbell, S., Hagger, M. S., Brown, V., \& Tidy, J. (2004). Appraisal theory and emotional sequelae of first visit to colposcopy following an abnormal cervical screening result. British Journal of Health Psychology, 9(4), 533-556. https://doi.org/10.1348/1359107042304560

Orbell, S., Hagger, M. S., Brown, V., \& Tidy, J. (2006). Comparing two theories of health behavior: A prospective study of non-completion of treatment following cervical cancer screening. Health Psychology, 25(5), 604-615. https://doi.org/10.1037/0278$\underline{6133.25 .5 .604}$

Orbell, S., Henderson, C. J., \& Hagger, M. S. (2015). Illness schema activation and the effects of illness seasonality on accessibility of implicit illness-related information. Annals of Behavioral Medicine, 49(6), 918-923. https://doi.org/10.1007/s12160-0159719-y

Orbell, S., Hodgkins, S., \& Sheeran, P. (1997). Implementation intentions and the theory of planned behavior. Personality and Social Psychology Bulletin, 23(9), 945-954. https://doi.org/10.1177/0146167297239004

Orbell, S., O'Sullivan, I., Parker, R., Steele, B., Campbell, C., \& Weller, D. (2008). Illness representations and coping following an abnormal colorectal cancer screening result. Social Science \& Medicine, 67(9), 1465-1474. https://doi.org/10.1016/j.socscimed.2008.06.039

Orbell, S., \& Phillips, L. A. (2019). Automatic processes and self-regulation of illness. Health Psychology Review, 13(4), 378-405. https://doi.org/10.1080/17437199.2018.1503559

Orbell, S., \& Sheeran, P. (1998). 'Inclined abstainers': A problem for predicting health related behaviour. British Journal of Social Psychology, 37(2), 151-165. https://doi.org/10.1111/j.2044-8309.1998.tb01162.x

Orbell, S., Szczepura, A., Weller, D., Gumber, A., \& Hagger, M. S. (2017). South Asian ethnicity, socio-economic status and psychological mediators of faecal occult blood colorectal screening participation: A prospective test of a process model. Health Psychology, 36(12), 1161-1172. https://doi.org/10.1037/hea0000525

Orbell, S., \& Verplanken, B. (2010). The automatic component of habit in health behavior: Habit as cue-contingent automaticity. Health Psychology, 29(4), 374-383. https://doi.org/10.1037/a0019596

Orbell, S., Zahid, H., \& Henderson, C. J. (2020). Changing behavior using the health belief model and protection motivation theory. In M. S. Hagger, L. D. Cameron, K. Hamilton, N. Hankonen \& T. Lintunen (Eds.), The handbook of behavior change (pp. 46-59). Cambridge University Press. https://doi.org/10.1017/97811086773180.004

Peters, G.-J. Y., Ruiter, R. A. C., \& Kok, G. (2013). Threatening communication: A critical re-analysis and a revised meta-analytic test of fear appeal theory. Health Psychology Review, 7, S8-S31. https://doi.org/10.1080/17437199.2012.703527

Petrie, K. J., Cameron, L. D., Ellis, C. J., Buick, D., \& Weinman, J. A. (2002). Changing illness perceptions after myocardial infarction: An early intervention randomized controlled trial. Psychosomatic Medicine, 64(4), 580-586. https://doi.org/10.1097/00006842-200207000-00007 
Petrie, K. J., \& Weinman, J. (2012). Patients' perceptions of their illness: The dynamo of volition in health care. Current Directions in Psychological Science, 21(1), 60-65. https://doi.org/10.1177/0963721411429456

Phillips, L. A., Diefenbach, M. A., Kronish, I. M., Negron, R. M., \& Horowitz, C. R. (2014). The necessity-concerns framework: A multidimensional theory benefits from multidimensional analysis. Annals of Behavioral Medicine, 48(1), 7-16. https://doi.org/10.1007/s12160-013-9579-2

Phillips, L. A., Leventhal, H., \& Leventhal, E. A. (2013). Assessing theoretical predictors of long-term medication adherence: Patients' treatment-related beliefs, experiential feedback and habit development. Psychology \& Health, 28(10), 1135-1151. https://doi.org/10.1080/08870446.2013.793798

Preacher, K. J., Curran, P. J., \& Bauer, D. J. (2006). Computational tools for probing interaction effects in multiple linear regression, multilevel modeling, and latent curve analysis. Journal of Educational and Behavioral Statistics, 31(4), 437-448. https://doi.org/10.3102/10769986031004437

Protogerou, C., Johnson, B. T., \& Hagger, M. S. (2018). An integrated model of condom use in sub-Saharan African youth: A meta-analysis. Health Psychology, 37(6), 586-602. https://doi.org/10.1037/hea0000604

Rhodes, R. E., \& de Bruijn, G. J. (2013). How big is the physical activity intention-behaviour gap? A meta-analysis using the action control framework. British Journal of Health Psychology, 18(2), 296-309. https://doi.org/10.1111/bjhp.12032

Roesch, S. C., \& Weiner, B. (2001). A meta-analytic review of coping with illness: Do causal attributions matter? Journal of Psychosomatic Research, 50(4), 205-219. https://doi.org/https://doi.org/10.1016/S0022-3999(01)00188-X

Rogers, R. W. (1975). A protection motivation theory of fear appeals and attitude change. Journal of Psychology, 91(1), 93-114. https://doi.org/10.1080/00223980.1975.9915803

Rutter, C. L., \& Rutter, D. R. (2002). Illness representation, coping and outcome in irritable bowel syndrome (IBS). British Journal of Health Psychology, 7(4), 377-391. https://doi.org/10.1348/135910702320645372

Scharloo, M., Kaptein, A. A., Weinman, J., Hazes, J. M., Willems, L. N. A., Bergman, W., \& Rooijmans, H. G. M. (1998). Illness perceptions, coping and functioning in patients with rheumatoid arthritis, chronic obstructive pulmonary disease and psoriasis. Journal of Psychosomatic Research, 44(5), 573-585. https://doi.org/10.1016/S00223999(97)00254-7

Schüz, B., Brick, C., Wilding, S., \& Conner, M. T. (2020). Socioeconomic status moderates the effects of health cognitions on health behaviors within participants: Two multibehavior studies. Annals of Behavioral Medicine, 54(1), 36-48. https://doi.org/10.1093/abm/kaz023

Schüz, B., Li, A. S.-W., Hardinge, A., McEachan, R. R. C., \& Conner, M. (2017). Socioeconomic status as a moderator between social cognitions and physical activity: Systematic review and meta-analysis based on the Theory of Planned Behavior. Psychology of Sport and Exercise, 30, 186-195. https://doi.org/10.1016/j.psychsport.2017.03.004

Schwarzer, R. (2008). Modeling health behaviour change: How to predict and modify the adoption and maintenance of health behaviors. Applied Psychology: An International Review, 57(1), 1-29. https://doi.org/10.1111/j.1464-0597.2007.00325.x

Selig, J. P., \& Little, T. D. (2012). Autoregressive and cross-lagged panel analysis for longitudinal data. In B. Laursen, T. D. Little \& N. A. Card (Eds.), Handbook of developmental research methods (pp. 265-278). Guildford Press. 
Seligman, M. E. P., Railton, P., Baumeister, R. F., \& Sripada, C. (2013). Navigating into the future or driven by the past. Perspectives on Psychological Science, 8(2), 119-141. https://doi.org/10.1177/1745691612474317

Sniehotta, F. F., Gorski, C., \& Araújo-Soares, V. (2010). Adoption of community-based cardiac rehabilitation programs and physical activity following phase III cardiac rehabilitation in Scotland: A prospective and predictive study. Psychology \& Health, 25(7), 839-854. https://doi.org/10.1080/08870440902915915

Spence, M. J., \& Moss-Morris, R. (2007). The cognitive behavioural model of irritable bowel syndrome: a prospective investigation of patients with gastroenteritis. Gut, 56(8), 1066. https://doi.org/10.1136/gut.2006.108811

Weinman, J., Petrie, K. J., Sharpe, N., \& Walker, S. (2000). Causal attributions in patients and spouses following first-time myocardial infarction and subsequent lifestyle changes. British Journal of Health Psychology, 5(3), 263-273. https://doi.org/10.1348/135910700168900

Weinman, J. A., Petrie, K. J., Moss-Morris, R., Broadbent, E., \& Sivertsen, B. (2018). The illness perception questionnaire. Retrieved July 13, 2018, from https://www.uib.no/ipq/

Weinman, J. A., Petrie, K. J., Moss-Morris, R., \& Horne, R. (1996). The illness perception questionnaire: A new method for assessing the cognitive representation of illness. Psychology and Health, 11(3), 431-445. https://doi.org/10.1080/08870449608400270

Zhang, C. Q., Zhang, R., Schwarzer, R., \& Hagger, M. S. (2019). A meta-analysis of the health action process approach. Health Psychology, 38(7), 623-637.

https://doi.org/10.1037/hea0000728 
Figure 1. The common sense model of illness self-regulation (Leventhal et al., 1992).

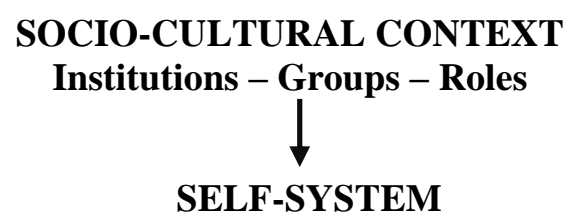

SELF-SYSTEM

Biological Characteristics - Psychological Traits

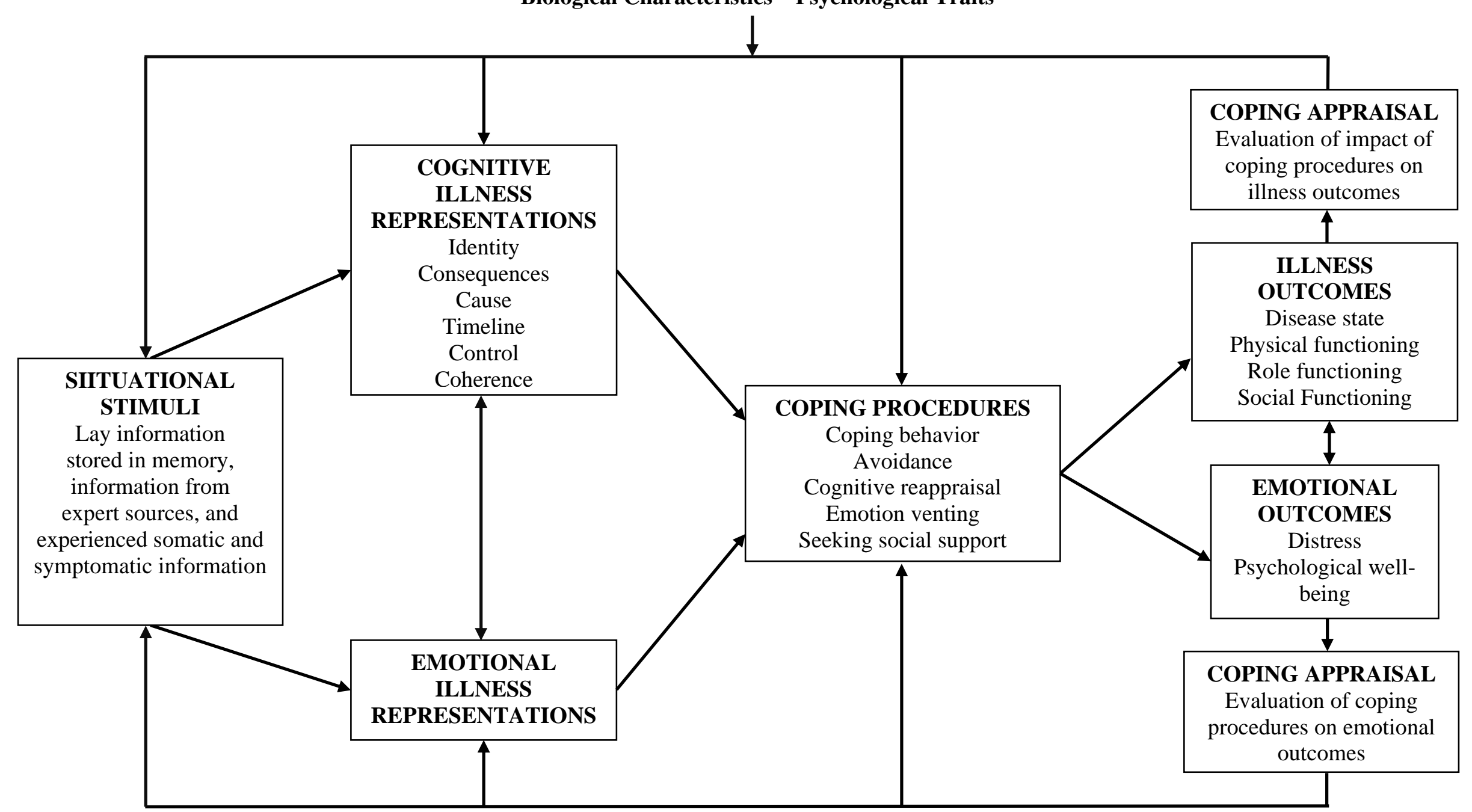


Figure 2. The extended common sense process model adapted from Hagger et al. (2017).

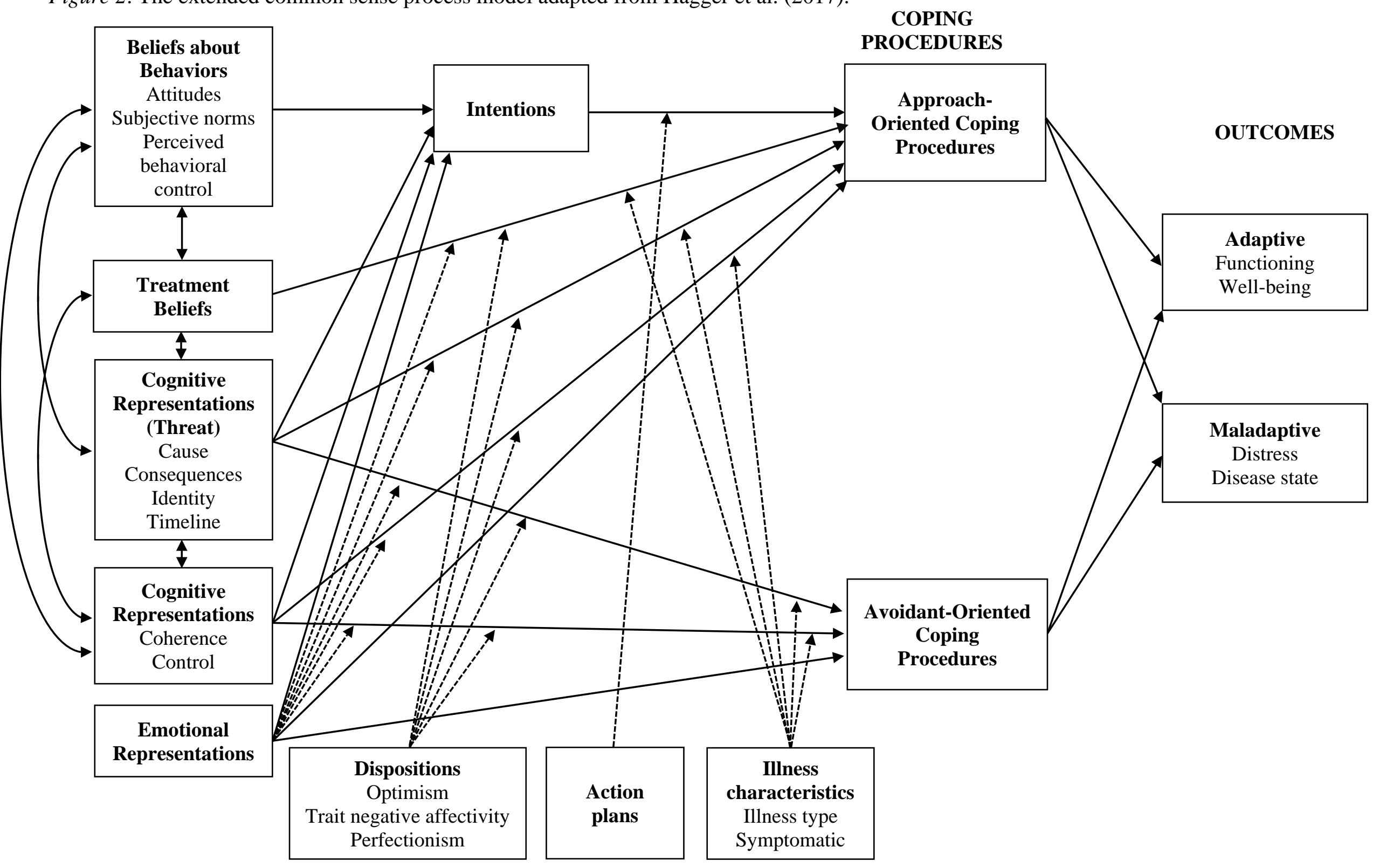

Note. Solid lines represent proposed effects of illness representation dimensions and beliefs about behaviors on coping procedures and effects of coping procedures on illness outcomes, and broken lines represent moderator effects. The following effects have been omitted for clarity: (a) Direct effects of cognitive and emotional representations on illness outcomes and (b) moderating effects of individual difference and illness characteristics on relations between coping and outcomes. 
Figure 3. Panel design testing stability, cross-lagged (reciprocal), and time-lagged effects of constructs of the common sense model over time.

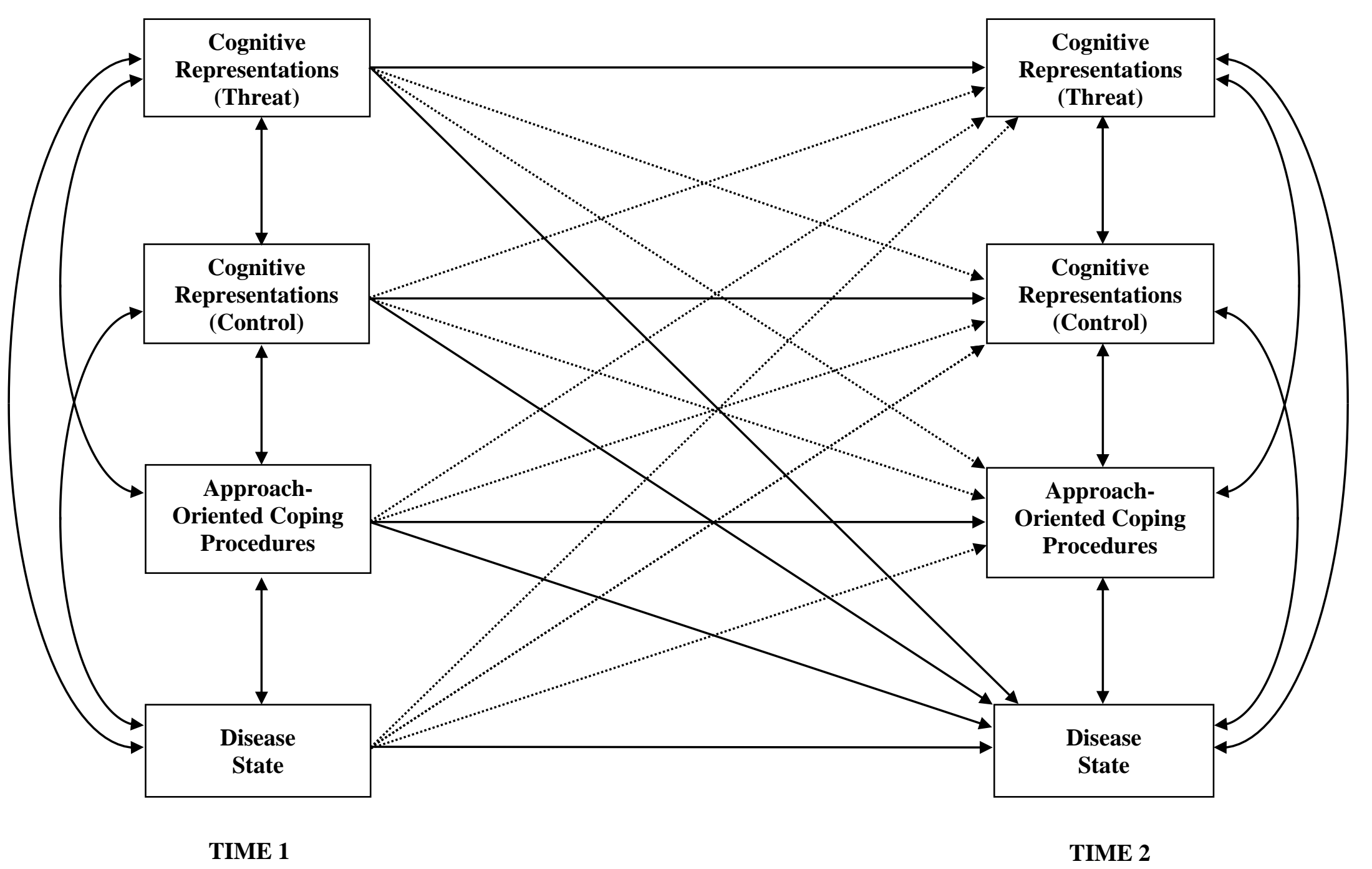

Note. Solid lines represent autoregressive effects and effects of representation and coping dimensions on illness outcomes. Broken lines represent reciprocal effects. Double headed arrows represent correlations among variables within time points. 
Figure 4. Independent effects of beliefs about coping behavior and illness representations on proposed pathways of the extended common sense model.

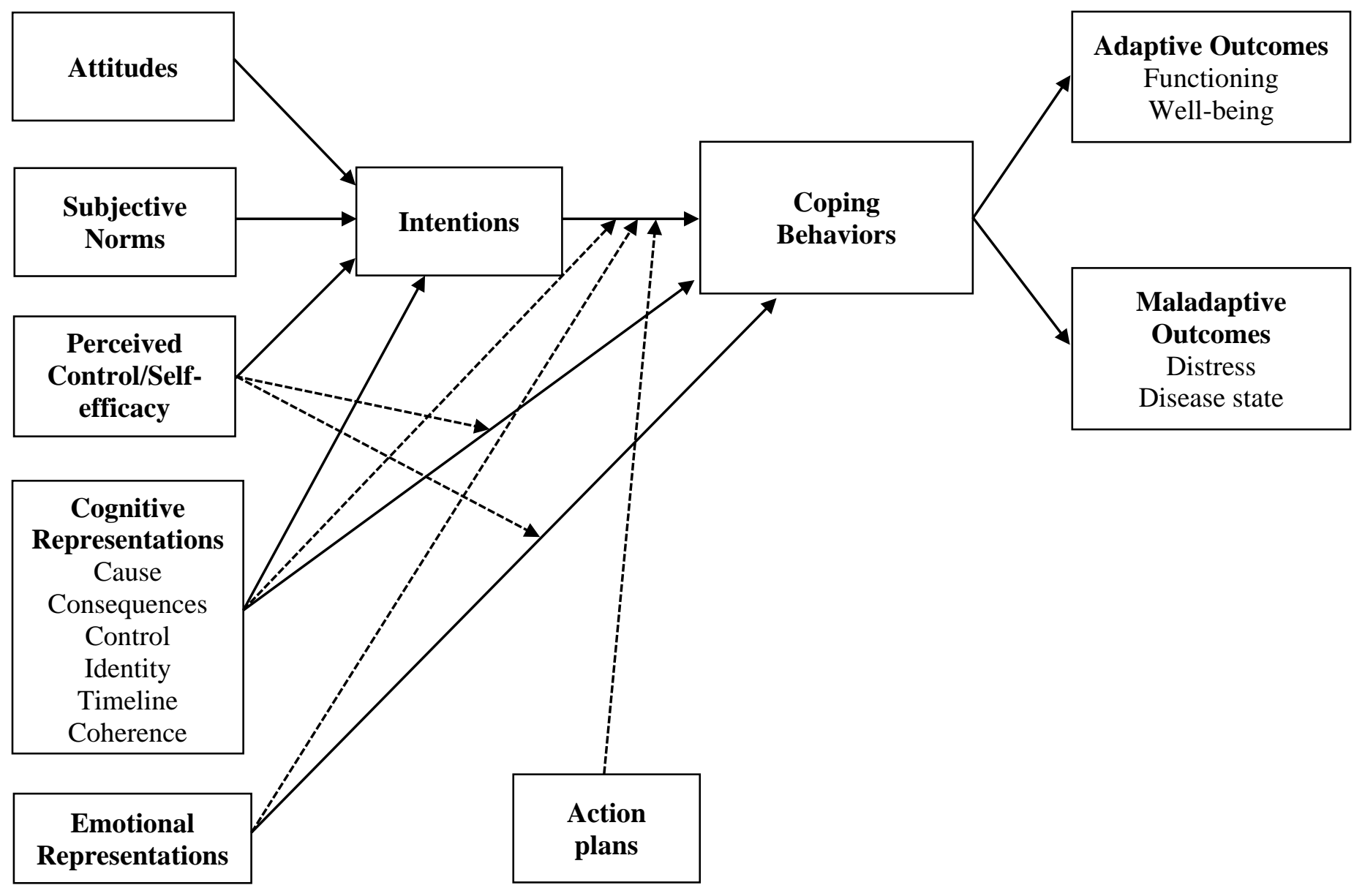

Note. Figure adapted from Hagger et al. (2017). Direct effects of cognitive and emotional representations on illness outcomes omitted for clarity. Higher scores for illness representation dimensions (identity, consequences, timeline, emotional representations) indicate greater threat, high levels of attitude, subjective norms, perceived behavioral control, and personal control indicate stronger beliefs, high levels of functioning and well-bring indicate adaptive outcomes, and high levels of distress and disease state indicate maladaptive outcomes. 
Figure 5. Moderating effects of trait negative affectivity on proposed pathways of the revised common sense process model, adapted from Hagger et al. (2017).

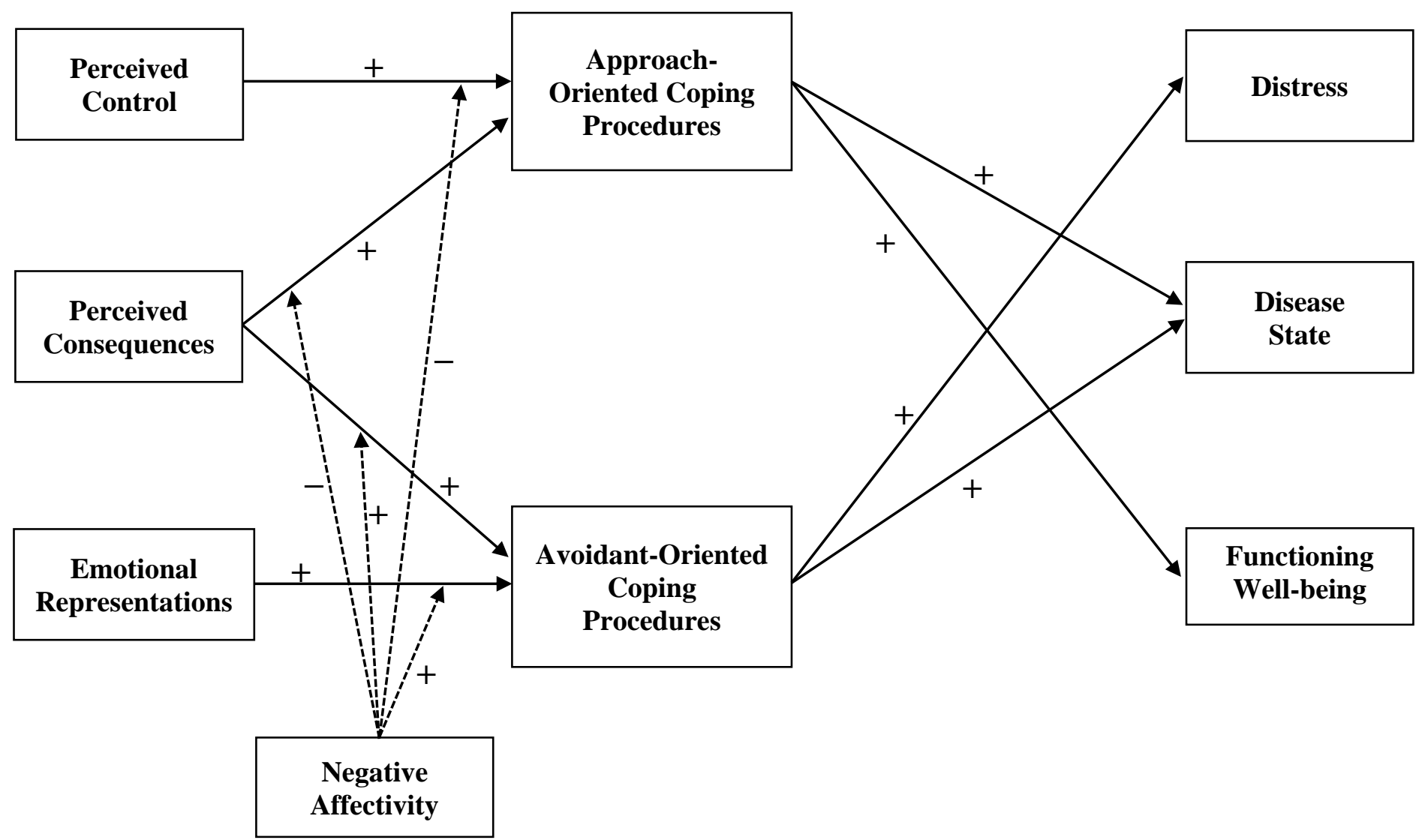

Note. Solid lines represent hypothesized effects of representations on coping procedures and effects of coping procedures on illness outcomes, and broken lines represent moderating effects. Direct effects of cognitive and emotional representations on illness outcomes omitted for clarity. Higher scores for illness representation dimensions (identity, consequences, timeline, emotional representations) indicate greater threat, high levels of functioning and well-bring indicate adaptive outcomes, and high levels of distress and disease state indicate maladaptive outcomes. 
Figure 6. Moderating effects of emotional representations on proposed pathways of the revised common sense process model, adapted from Hagger et al. (2017).

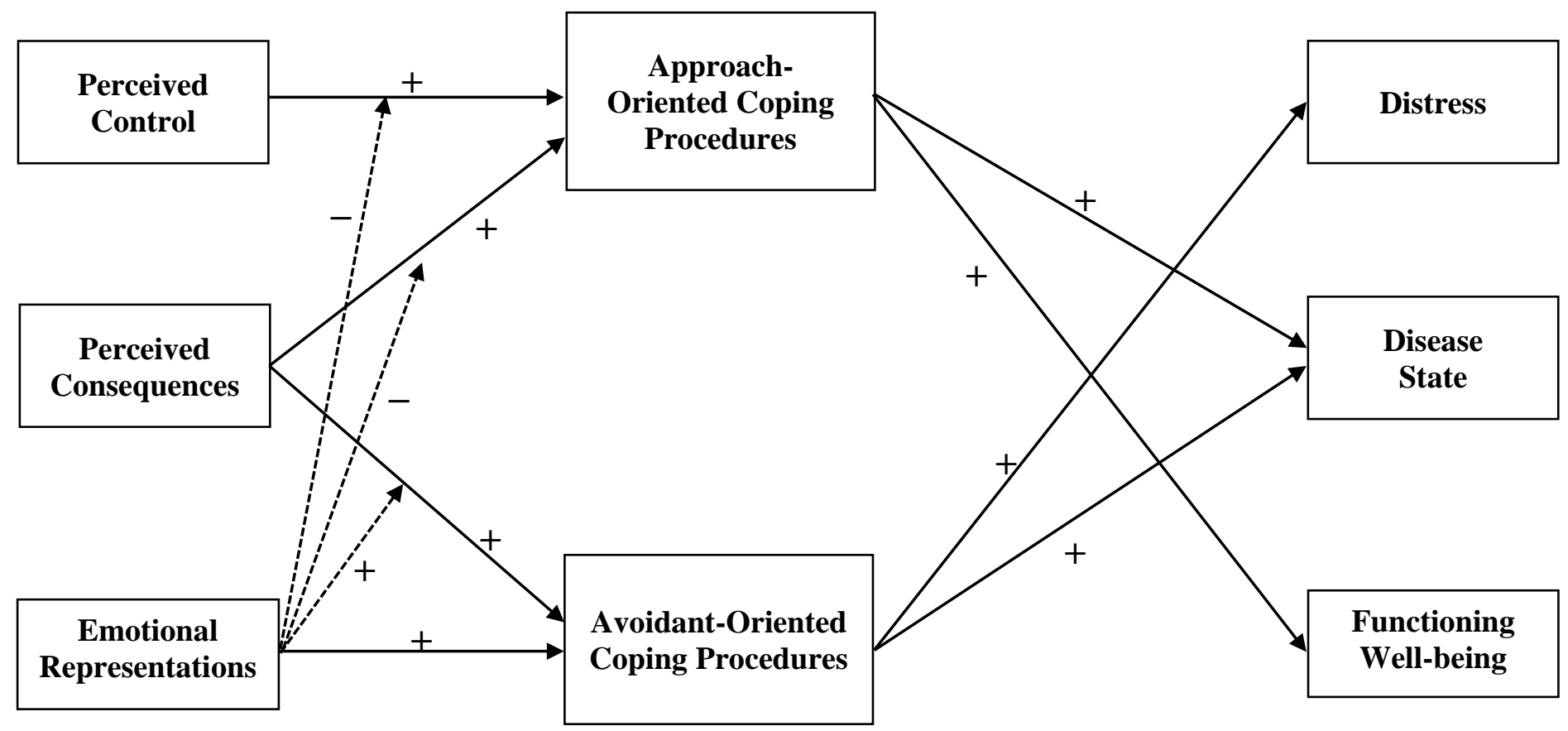

Note. Solid lines represent hypothesized effects of representations on coping procedures and effects of coping procedures on illness outcomes, and broken lines represent moderating effects. Direct effects of cognitive and emotional representations on illness outcomes omitted for clarity. Higher scores for illness representation dimensions (identity, consequences, timeline, emotional representations) indicate greater threat, high levels of functioning and well-bring indicate adaptive outcomes, and high levels of distress and disease state indicate maladaptive outcomes. 